\title{
Exploring Public Attitudes toward E-Government Health Applications Used During the COVID-19 Pandemic: Evidence from Saudi Arabia
}

\author{
Dalal Bamufleh ${ }^{1}$, Amani Saud Alshamari ${ }^{1}$, Asrar Saud Alsobhi ${ }^{1}$, Hanan Hisham Ezzi ${ }^{1}, \&$ Waad Sultan Alruhaili ${ }^{1}$ \\ ${ }^{1}$ Yanbu University College, Yanbu, Saudi Arabia \\ Correspondence: Dalal Bamufleh, Management Science Department- Management Information Systems, Yanbu \\ University College, Yanbu, Saudi Arabia.
}

Received: April 30, 2021

Accepted: May 28, $2021 \quad$ Online Published: June 10, 2021

doi:10.5539/cis.v14n3p1

URL: https://doi.org/10.5539/cis.v14n3p1

\begin{abstract}
This study sought to explore factors that determine the public's acceptance of and adoption behavior toward e-government health applications launched in Saudi Arabia (SA) by the Ministry of Health (MOH) during the COVID-19 pandemic. The research relied on several theories: the technology acceptance model (TAM), information system success model (ISSM), mobile services acceptance model (MSAM), and unified theory of acceptance and use of technology (UTAUT). The constructs of perceived ease of use (PEOU), perceived usefulness (PU), attitude (ATT), trust (TR), information quality (IQ), facilitating condition (FC), and social influence (SI) were utilized to investigate the user's intention toward using e-government health applications. The proposed model and its seven hypotheses were tested by conducting a survey across social media among citizens and residents in SA. A total of 785 valid responses were analyzed by SmartPLS and a structural equation modeling technique. After analysis, the results showed that PEOU, PU, ATT, TR, IQ, FC, and SI have positive effects on behavioral intentions. As for contributions, this paper is the first research paper to investigate the adoption of e-government health applications launched by MOH in SA during the COVID-19 pandemic and to provide a theoretical framework for pursuing future research work in a similar scope.
\end{abstract}

Keywords: e-government, e-health, technology adoption, applications

\section{Introduction}

Over the course of many years, the health sector in Saudi Arabia (SA) has improved the quality of the medical services it provides. With higher demand for technology, the Saudi government invested in adopting and developing e-government. With the sudden spread of COVID-19, the MOH released several more mobile health applications to serve the public in SA: Mawid, Tetamman, Tawakkalna, and Tabaud. With these applications, citizens and residents can request movement permits during curfew, book COVID-19 test appointments, and receive medical consultations $(\mathrm{MOH}, 2020 \mathrm{c})$. Adopting such technology provides benefits to health-care providers, such as safer hospital operations and better accessibility to patient's data. From a patient's perspective, there are also advantages, such as receiving better treatment quality and saving time (Amin et al., 2020), but also differing opinions toward the use of such technologies in a health-care context.

In light of the developing technology, SA adopted e-government practices to improve the provision of public services, which include the health sector. This led to the adoption of e-health practices to improve the health-care system in SA (Aljohani \& Chandran, 2019). During the COVID-19 pandemic, the Saudi government and the $\mathrm{MOH}$ launched several applications that serve different purposes to ensure that the public is receiving medical treatment in the safest way possible. Adopting e-health reflects significant improvements and changes to the health-care system by helping to reduce the number of medication mistakes and improving the accessibility, efficiency, and effectiveness of medical services (Domenichiello, 2015). However, developing and adopting such technology require an enormous contribution of money, time, and effort, all of which could be wasted if the public does not accept and use those applications to their full potential (Okour et al., 2019). Hence, this paper focuses on the public's perceptions regarding these technologies.

The study authors aimed to identify the current state of e-government health applications used in SA during the COVID-19 pandemic by surveying the public and reading the research papers and articles written within the same scope. In furtherance of that aim the study authors asked the question, "What is the current status of e-government health applications in SA during COVID-19?" The second aim was to identify the factors that 
could affect public acceptance and behavior toward e-health applications, which would answer the question, "What are the potential factors that could affect the public acceptance of e-government health applications during COVID-19?" According to works in the literature that share the same scope of this study, factors that could affect public acceptance of e-health applications would be individual perceptions, technical complexities, social influences, trends (Aljohani \& Chandran, 2019), ease of use, and system security (Ramdani et al., 2020). The study authors proposed a model and validated it by surveying the public in SA. By this strategy, the state of e-government health application adoption could be recognized.

\section{Literature Review}

In the literature review, the study authors discuss four main parts. In the first part, the concept of e-government is defined. The second part explains e-health from various aspects. The third part discusses in detail technology adoption and its various models, and the fourth part discusses studies addressed e-government health application adoption.

\subsection{E-Government}

E-government is defined as "an Internet-worked government which links new technology with legal systems internally and in turn links such government information infrastructure externally with everything digital and with everybody - the taxpayer, suppliers, business customers, voters, and every other institution in the society" (Tapscott, 1996). E-government can also be defined as "the electronic interaction (transaction and information exchange) between the Government, the public (citizens and businesses) and employees" (Abramson and Morin, 2003). Alshehri and Drew (2012) provided a general definition for e-government that involves "the use of information and communication technologies, and particularly the Internet, as a tool to achieve better government." According to Kharel and Shakya (2012), e-government is the "delivery of national or local government information and services via internet or other digital means to citizens or businesses or other governmental agencies. E-Government is creating a comfortable, transparent, and cheap interaction between government and citizens (G2C), government and business enterprises (G2B) and relationship between government agencies (G2G inter-agency relationship). Additionally, e-government is known as "the use of information technology in general, to improve the delivery of government services and activities in the public sector, such as: providing citizens with more convenient access to information and services, and providing effective delivery of government services to citizens and businesses as well as improving the performance of government employees" (Turban et al., 2017). In a recent study by Shkarlet et al. (2020), e-government is defined as "the application of ICT [information and communications technology] to government functions based on the use of the latest achievements in the field of digitization, creation of the latest tools for the development of the information society, and ensuring the efficiency, openness and transparency of the activity of public authorities."

The utilization of e-government can provide many benefits and advantages. According to Saurabh (2017) and Ndou (2004), e-government is capable of offering an extraordinary portfolio of public services in an accessible and cost-effective way. It provides the user easy access to the most accurate information available without wasting time, resources, and money. Also, the anticipated benefits of e-government include efficiency, improved services, better accessibility of public services, sustainable community development, transparency and accountability, reduced difficulties for business, immediate information provision, and the speedy administration of services and information.

Contrarily, the disadvantages of adopting e-government practices are high costs; information technology (IT) infrastructure vulnerability in the government sector; and lack of public government expertise, information protection and privacy systems, and trained IT and government service specialist staff (Abanumy \& Mayhew, 2005).

\subsection{E-Government Practices in Saudi Arabia}

E-government represents a fundamental change to the public sector, from processes and functions to public services provision. Because information and communications technology (ICT) showed its importance in several nations' economies, SA decided to implement it in several fields, such as finance, commerce, government, and health, to enhance productivity and performance (Al-Sudairi, 1994; Al-Turki \& Tang, 1998; Sait et al., 2003). Information technology plans were launched in 2001, including several e-government initiatives, supporting the use of ICT to redesign public organizations and setting objectives that focus on three main areas: e-readiness, e-society, and IT training in SA (Ministry of Communication and Information Technology [MICT], 2020). In 2003, a program called YESSER was launched in SA, which is considered an e-government program developed 
to accomplish growth in the public sector and continue development within government (MICT, 2020). The YESSER program applies to all e-government operations, systems, regulations, and other relevant matters. YESSER is an umbrella term, and it serves as the controller of the government. The country's first national e-government policy was introduced in 2005 by the Saudi government. The program was launched and regulated in cooperation with three entities: the MICT, the Ministry of Finance and Communication, and the IT Commission (Alfarraj et al., 2013). The goal of this initiative was to establish user-centered electronic programs focused on enhancing public sector government services. SA's vision is to embrace and enable connectivity and IT structures that contribute to realizing an IT society and a digital economy (Alateyah et al., 2013). Another e-government application that was launched by SA is called Absher, which is an e-services mobile application platform launched by the Interior Ministry. It is divided into two e-services: integrated e-services for individuals, which was released in 2015, and e-services for businesses, which was released in 2017. Absher for individuals includes more than 200 e-services that pertain to civil affairs, passports, and traffic. The user can book an appointment to renew or obtain an ID card, renew their passport or driver's license, check for any traffic violations, inquire about current transactions or personal data, report lost documents, inquire about a work visa, and more. Absher for businesses pertains to business people dealing with labor issues, for example, issuance or renewal of residency, visa issues, requesting a resident report, and updating labor passport data (Absher, 2021).

\subsection{E-Health}

ICT in the health industry has proved its potential to improve the quality of the medical services provided. Redesigning health services in line with ICT to establish e-health practices is considered a significant shift in the health industry (Sezgin et al., 2014).

E-health is defined as "describing the application of ICT across the whole range of functions that affect the health sector. Essentially, it refers to tools and services using ICT that can improve prevention, diagnosis, treatment, monitoring and management" (Domenichiello, 2015). In other words, e-health is a form of mobile health (m-health), which involves all forms of electronic healthcare delivered via ICT channels, ranging from informational, educational, and commercial; to direct services offered by healthcare organizations, professionals, and consumers themselves (Alsulame et al., 2016). Based on Aljohani and Chandran (2019), m-health likewise is "the use of mobile technologies such as smartphones, tablets, and portable digital devices to improve health practices." Also, e-health refers to "the use of mobile devices - such as mobile phones, patient monitoring devices, personal digital assistants (PDAs) and wireless devices-for medical and public health practice" (Ramdani et al., 2020).

E-health has different forms, such as mobile health applications (MHAs), hospital information systems (HISs), telemedicine, electronic health records (EHRs), and remote patient monitoring (RPM) devices.

E-health implementation offers benefits to patients; service providers, such as doctors and nurses; and health-care systems. With e-health, patients can access more reliable health information through the internet, anytime 24/7; obtain a quick initial diagnosis, especially when they cannot reach the hospital; and continuously track and record their health status (Baatia, 2017; Ramdani et al., 2020). Service providers have access to more reliable information based on facts that would support decision-making and allow them to communicate with other colleagues. Also, adopting e-health reflects significant improvements and changes to health-care systems; it can reduce the number of medication mistakes; decrease medical costs; and improve the accessibility, efficiency, and effectiveness of medical services.

Furthermore, adopting MHAs, which are a form of e-health, results in safer hospital operations, better treatment quality, and improved efficiency and data accessibility by clinicians and patients. The applications also offer the knowledge exchange and technology transfer that allows the health facility to improve the decision-making process to provide the best decision regarding an issue and up-to-date patient information (Okour et al., 2019).

Contrarily, adopting e-health is not an easy process and comes with many challenges. Adopting ICT in the health sector takes a long time, compared to its implementation in other sectors, which could be due to the complex nature of medical services and personal data sensitivity (Domenichiello, 2015). Despite the benefits of using MHAs in health care, a study showed that several MHA projects were withdrawn at early stages due to barriers such as lack of funds, infrastructure issues, rejection and resistance by health-care providers and professionals. Furthermore, adopting such technology requires capitalization and a massive investment to fund the project (Okour et al., 2019). Moreover, using e-health technologies requires education and training, which represents one of the adoption barriers. All medical staff should have a basic knowledge of and be thoroughly trained in how to use the technology, to avoid possible obstacles. The public should also be supported with educational materials on using the technology provided for them (Khalil \& Jones, 2007). Also, adopting e-health requires 
much supervision and regulation. Licensing and hiring specialists and consultants of telemedicine services represent other challenges (Khalil \& Jones, 2007). Table 1 summarizes E-Health forms definitions.

Table 1. E-Health Forms Definitions

\begin{tabular}{ll}
\hline E-Health Form & Definition \\
\hline $\begin{array}{l}\text { Mobile health } \\
\text { application }\end{array}$ & $\begin{array}{l}\text { "A collective of diverse information instruments, which includes emergency information, test systems, } \\
\text { electronic prescription, telemedicine, and digital imagery, among others" (Okour et al., 2019). }\end{array}$ \\
$\begin{array}{l}\text { Hospital } \\
\text { information } \\
\text { system (HIS) }\end{array}$ & $\begin{array}{l}\text { "A Hospital Information System (HIS) is a comprehensive, integrated information system designed to } \\
\text { manage the administrative, financial and clinical aspects of a hospital. As an area of medical } \\
\text { informatics, the aim of hospital information system is to achieve the best possible support of patient } \\
\text { care and administration by electronic data processing" (Ismail et al., 2010). }\end{array}$ \\
$\begin{array}{l}\text { According to WHO, telemedicine is "the delivery of healthcare services, where distance is a critical } \\
\text { factor, by all healthcare professionals using ICT for the exchange of valid information for the } \\
\text { diagnosis, treatment, and prevention of disease and injuries, research and evaluation, and for the }\end{array}$ \\
$\begin{array}{l}\text { continuing education of healthcare providers, all in the interests of advancing the health of individuals } \\
\text { and their communities". } \\
\text { "Electronically collecting and storing data about patients, supplying that information to providers on } \\
\text { request and permits physicians to enter patient care orders on the computer" (Khalil \& Jones, 2007). }\end{array}$ \\
$\begin{array}{l}\text { Electronic health } \\
\text { records (EHR) }\end{array}$ \\
$\begin{array}{l}\text { Remote patient } \\
\text { monitoring } \\
\text { (RPM) }\end{array}$ & $\begin{array}{l}\text { and physical activity. It may come in the form of digital health applications and wearable devices, and } \\
\text { both provide a higher rate of the correct reading (Mosnaim et al., 2021). }\end{array}$ \\
\hline
\end{tabular}

\subsection{E-Health Practices in Saudi Arabia}

MOH applied e-health technologies to renovate and diversify health services in SA so that the health sector would meet the standards necessary to fulfill Saudi 2030's vision. MOH set more than 40 initiatives to improve the health-care system to fulfill the public's current and future needs (MOH, 2021). MOH's vision is "to be the most commonly used channel by the recipients of the MOH information and awareness services and turn into the most important interaction, and communication tool in a manner that supports the principle of participation and constructive dialogue" (MOH, 2019). The mission is to "provide accurate information to the portal's public visitors as well as raising health awareness in general, meanwhile trying to highlight the best health practices and seeking to improve the Kingdom's health sector" (MOH, 2019). The MOH built a new application in 2017 to conduct online medical consultations with personal physicians and book primary health-care appointments (MOH, 2018). According to a report in 2019 by the National Digital Transformation Unit, the application received low use and acceptance by its intended users.

According to the Global Health Security Index (2019), "Saudi health security is ranked 47th of 195 globally." King Faisal Specialist Hospital \& Research Centre (KFSH \& RC) is considered the first integrated digital hospital to provide virtual clinics and tele-ICU services. KFSH \& RC has set the country's standards by providing unique and quality tertiary care services that are considered the best in the Eastern Mediterranean region.

$\mathrm{MOH}$ provides several health programs and applications launched from the beginning of the COVID-19 pandemic in SA. Following the World Health Organization (WHO, 2020) guidelines to deal with this virus's spread, MOH specified a strategy considering those guidelines. The strategy included developing dashboards linked to the National Health Observatory to share the statistics of the total and daily confirmed cases and deaths. The strategy also involves the implementation of m-health; telehealth; virtual clinics; and robotics, all which identified several suspected cases through mobile applications. These technologies will revolutionize health services and the health system well beyond the outbreak of COVID-19 (Global Health Exhibition, 2020). According to Dr. Amr Jamal, a founding member of the Saudi Association for Health Informatics, "since the confirmation of the first COVID-19 case in the country which was on 2 March 2020, the digital transformation of the healthcare system that has taken place in SA has been tremendous, equaling and surpassing what the country has tried to achieve in the last four to five years on its journey to digital transformation" (Global Health Exhibition, 2020).

On March 25, 2020, MOH updated the Mawid app, which can guide citizens and residents to self-evaluation services for symptoms of COVID-19 (Sabq, 2020). MOH initially launched the application in May 2019 as part of its plan to implement digital technology in the SA health-care system (Naar, 2020). The Mawid app "is a free electronic service that enables the patients to book their appointments at 2400 primary healthcare centers around 
the kingdom in coordination with the concerned department" (MOH, 2020b). Patients can change, amend, or cancel their medical appointments and manage their referral appointments at any hospital via the Mawid app (MOH, 2020b). Through answering questions on user health, travel history, and contacts over the past 14 days, the Mawid app can approximate the individual's risk status and provide the appropriate advice.

The Tetamman app is one of the MOH applications, launched on April 11, 2020, aimed at following up with health conditions and home isolation of citizens and residents. All beneficiaries can use the Tetamman app if they have symptoms, have come into contact with confirmed cases of COVID-19, or come from outside the Kingdom (MOH, 2020d). According to the MOH (2020d) website, Tetamman app services include an educational library, updated data on contacts of confirmed cases, examination results, daily health status follow-up, links to epidemiological investigation support, and a countdown indicator for health isolation.

Another application is Tawakkalna, which was developed by the Information Affiliate Center and the Saudi Data and Artificial Intelligence Authority (SDAIA). Tawakkalna was launched on May 4, 2020, to issue movement permits electronically during the curfew period, in cooperation with the $\mathrm{MOH}$ and all relevant authorities, to reduce the spread of the pandemic in the Kingdom (Aleqtisadiah, 2020; SDAIA, 2020a). Namely, the Tawakkalna app shows its users their health status through colored codes at the highest degree of safety and privacy. It allows individuals to report infected cases or gatherings that violate the adopted precautionary measures (SDAIA, 2020a).

The Tabaud application was developed by SDAIA on June 14, 2020 (Okaz, 2020a), to notify users of their contact with people infected with COVID-19 (SDAIA, 2020b). It uses Bluetooth Low Energy and exposure notification technology (Saudi Press Agency, 2020). This technology was developed by Apple and Google to help governments and health agencies reduce the spread of COVID-19 through contact tracing (SDAIA, 2020b). The app can detect another device in its vicinity and exchange the convergent information. The app is linked with $\mathrm{MOH}$ data to confirm the collected information (infected or not infected). Then, the app sends notifications to all smartphones close by an infected person (SDAIA, 2020b).

\subsection{Technology Adoption}

Technology adoption is defined as "a sociological model that describes the adoption or acceptance of users to a new product or innovation according to the demographic and psychological characteristics of specific groups" (Al Moustapha, 2019). The following sections describe some of the technology adoption theories. Numerous studies in the literature emerge several models to understand and anticipate users' behaviors toward the new technologies' adoption and use. Moreover, several studies proposed new models by integrating measures from multiple models (Bamufleh et al., 2021).

\subsubsection{Theory of Reasoned Action}

The theory of reasoned action (TRA) was developed by Fishbein and Ajzen in 1975. TRA is a model for studying "social psychology that searches to identify the determinant factors of the consciously intentional behavior" (Fishbein \& Ajzen, 1975). It is suggested that an individual's behavioral intention (BI) is determined by attitudes (ATT) and subjective norms (SN) (Fishbein \& Ajzen, 1975). Attitude toward behavior (ATB) is the "individual positive or negative feelings (evaluative effect) shown to execute target behavior" (Witarsyah, 2018). SN refers to the impact of people who are important to the user on the user's perception to use the technology (Witarsyah, 2018).

\subsubsection{Theory of Planned Behavior}

Ajzen established the theory of planned behavior (TPB) in 1991. TPB extended TRA by adding perceived behavioral control (PBC; Venkatesh et al., 2003). TPB predicts an individual's ATT and explains human behavior in specific contexts. TPB has three constructs: (a) ATB, adapted from TRA, refers to a particular behavior influenced by a combination of two related factors, our beliefs about the outcome of the behavior and our evaluation of the potential outcome, and also depends on an individual's past experiences (Matthew \& Kan, 2017); (b) SN, adapted from TRA, refers to being affected by the perceptions of those around us, such as family members, friends, and colleagues, and may affect one's performance of the behavior (Matthew \& Kan, 2017); and (c) PBC is "the perceived ease or difficulty of performing the behavior" (Ajzen, 1991, p. 188).

\subsubsection{Technology Acceptance Model}

Davis developed the technology acceptance model (TAM) in 1989 to understand why a user accepts or rejects new technology. There are four constructs in TAM: (a) perceived usefulness (PU), which is "the degree to which a person believes that using a particular system would enhance his or her job performance" (Davis, 1989, p. 320); 
(b) perceived ease of use (PEOU), which is "the degree to which a person believes that using a particular system would be free of effort" (Davis, 1989, p. 320); (c) SN, adapted from TRA and TPB, which is "the influence of people in one's social environment on his behavioral intentions; beliefs, weighted by the importance one attributes to each of their opinions that will influence one's behavioral intention" (Fishbein \& Ajzen, 1975); and (d) attitude (ATT), which is "the impression or impact on the technology" (Davis, 1989).

\subsubsection{Technology-Organization-Environment}

The technology-organization-environment (TOE) framework was described by Tornatzky and Fleischer (1990) as being the processes of technological innovation. The TOE framework is an organization-level theory that hypothesizes that three elements of an organization influence its technology adoption decision: technological context (TC), organizational context (OC), and environmental (EC) context. The TC includes the internal and external technologies relevant to the adoption of e-health in hospitals. Hospitals should guarantee that the ICT infrastructure, software, and hardware are available in the market. The OC covers organization scope, planning and organizing an organization's resources, organizational culture, managerial structure, human resources quality, and financial resources. Lastly, the EC studies the regulations and policies of health-care organizations and their relation to health information technology (HIT) readiness (Yusif et al., 2020).

\subsubsection{Model of Personal Computer Utilization (MPCU)}

Thompson and colleagues developed the model of personal computer utilization (MPCU) in 1991 to estimate the use of personal computers (PCs). This theory is mainly used in sociological and psychological studies to understand the construction factors affecting the individual's behavior in using a PC. The constructs of the MPCU are as follows: (a) job fit (JF), "the extent to which an individual believes that the use of technology can improve the performance of his work" (Thompson et al., 1991, p. 129); (b) complexity (CX; based on Rogers and Shoemaker [1971], "the extent to which an innovation deems to be as light as possible and is difficult to understand and use"; (c) long-term consequences (LTC), "outcomes that have a payoff in the future" (Thompson et al., 1991, p. 129); (d) affect toward use (ATU); based on Triandis (1980), "feelings of joy, elation, or pleasure, or depression, disgust, displeasure, or hate associated by an individual with a particular act"; (e) social factors (SF), "the internalization of individuals from subjective cultural reference groups and inter-personal agreements made with others, in certain social situations" (Triandis, 1980); and (f) facilitating conditions (FC), "provision of support for users of PCs may be one type of FC that can influence system utilization" (Thompson et al., 1991, p. 129).

\subsubsection{Motivational Model}

Davis and colleagues developed the motivational model (MM) in 1989, to examine what motivations drive a person to use a computer at work (Witarsyah, 2018). MM has two constructs: (a) extrinsic motivation (EM), "perception where users want to perform an activity because they perceive it as a tool in achieving the results, but different from the activity itself" (Witarsyah, 2018), and (b) intrinsic motivation (IN), "perceptions where users want to perform an activity because there is no obvious strong reason other than the process of doing the activity itself" (Witarsyah, 2018).

\subsubsection{Information Systems Success Model}

The information systems success model (ISSM) was developed by DeLone and McLean in 1992. The ISSM is defined as "an information system (IS) theory which seeks to provide a comprehensive understanding of information system success by identifying, describing, and explaining the relationships among six of the most critical dimensions of success along which information systems are commonly evaluated." The six dimensions are as follows: (a) system quality (SQ), "measures of the information processing system itself"; (b) information quality (IQ), used to measure "the quality of the information that the system produces"; (c) Intention to use (USE), "recipient consumption of the output of an information system"; (d) user satisfaction (USF), "recipient response to the use of the output of an information system"; (e) individual impact (II), "the effect of information on the behavior of the recipient"; and (f) organizational impact (OI), "the effect of information on organizational performance" (DeLone \& McLean, 1992).

\subsubsection{Combined TAM and TPB (C-TAM-TPB)}

C-TAM-TPB was introduced by Taylor and Todd in 1995. It is a multidimensional model that explains a person's behavior by combining constructs from both the TAM and TPB models. The constructs from the TAM model are PU and SN, and the constructs from the TPB are ATB and PBC (Taylor \& Todd, $1995 \mathrm{a}$ and b). 


\subsubsection{Unified Theory of Acceptance and Use of Technology}

Venkatesh and colleagues created the unified theory of acceptance and use of technology (UTAUT) in 2003. The UTAUT "is an attempt to provide a unified view of user acceptance of technology by integrating components from eight models' theories" (Wahdain \& Ahmad, 2014). The eight models are Social Cognitive Theory (SCT), TAM, MM, TRA, TPB, C-TAM-TPB, MPCU, and Integration of Innovation Diffusion Theory (IDT). The UTAUT is used for explaining user intentions to use an information system and subsequent usage behavior. UTAUT can explain up to 70\% of the variance (Bamufleh et al., 2020) The key constructs from the eight models are as follows: (a) performance expectancy (PE), "it was expected (from a theoretical point of view) that although gender and age moderate the relationship between PE and intention to use (ITU), studies have shown recently that taking into account the gender factor alone results in misleading results unless the age factor is taken into account too" (Venkatesh et al., 2003); (b) effort expectancy (EE), "the degree to which an individual believes that using the system will help him or her to attain gains in job performance" (Venkatesh et al., 2003, p. 447); (c) social influence (SI), "the degree to which an individual perceives that important others believe he or she should use the new system" (Venkatesh et al., 2003, p. 451); and (d) facilitating condition (FC), "the degree to which an individual believes that an organizational and technical infrastructure exists to support use of the system" (Venkatesh et al., 2003, p. 453).

\subsubsection{Fit between Individuals, Task, and Technology}

The fit between individuals, task, and technology (FITT) model was developed by Ammenwerth and colleagues in 2006. The model is based on the idea that "IT adoption in a clinical environment depends on the fit between the attributes of the users (e.g., computer anxiety, motivation), of the attributes of the technology (e.g., usability, functionality, performance), and of the attributes of the clinical tasks and processes (e.g., organization, task complexity)" (Ammenwerth et al., 2006). Individuals can be either one user or a group of users. Technology can be hardware, software, or network and extends to tools used by individuals to accomplish a task (paper-based tools). A task "comprises the wholeness of tasks and working processes that have to be completed by the user and that are supported by the given technology" (Ammenwerth et al., 2006). The three constructs-individual, technology, and task - affect each other, where an individual must have enough knowledge and motivation to perform a particular task. Then, technology should provide functionality and high performance to assist clinical tasks. Moreover, the user should get adequate training to use the technology. Therefore, insufficiency in fit between the three constructs may lead to problems during the projects' implementation (Ammenwerth et al., 2006).

\subsubsection{Mobile Services Acceptance Model (MSAM)}

The mobile services acceptance model (MSAM) was developed by Gao and colleagues in 2014. Gao et al. stated that mobile services' prevalence depends on how advanced the services are and user acceptance. The constructs comprising the MSAM are as follows: (a) context "provides an understanding of the way and circumstances for performing an activity" (Basole, 2004); (b) trust (TR) is defined as "a user's belief or faith in the degree to which a specific service can have no security and privacy threats" (Gao et al., 2008); (c) personal initiatives and characteristics (PIC) covers many constructs, including past experience with specific technology, personal innovativeness (Agarwal \& Prasad, 1998), perceived enjoyment (Heijden, 2004), personal willingness, social image and economic status" (Gao et al., 2014); and (d) PU and PEOU from the TAM (Davis, 1989). Refer to Table 2 for a summarization of all the technology adoption models discussed herein. 
Table 2. Model's summary

\begin{tabular}{|c|c|c|c|}
\hline User Acceptance of Technology & Year & Developers & Core Constructs \\
\hline $\begin{array}{l}\text { Theory of Reasoned Action } \\
\text { (TRA) }\end{array}$ & 1975 & $\begin{array}{l}\text { Fishbein \& } \\
\text { Ajzen }\end{array}$ & $\begin{array}{l}\text { Behavioral Intentions, Attitude Toward Behavior, } \\
\text { Subjective Norm. }\end{array}$ \\
\hline $\begin{array}{l}\text { Theory of Planned Behavior } \\
\text { (TPB) }\end{array}$ & 1988 & Ajzen & $\begin{array}{l}\text { Attitude Toward Behavior, Subjective Norm, } \\
\text { Perceived Behavioral Control. }\end{array}$ \\
\hline $\begin{array}{c}\text { Technology Acceptance Model } \\
\text { (TAM) }\end{array}$ & 1989 & Davis & $\begin{array}{l}\text { Perceived Usefulness, Perceived Ease of Use, } \\
\text { Subjective Norm, Attitude }\end{array}$ \\
\hline $\begin{array}{l}\text { Technology-Organization-Enviro } \\
\text { nment (TOE) }\end{array}$ & 1990 & $\begin{array}{l}\text { Tornatzky \& } \\
\text { Fleischer }\end{array}$ & $\begin{array}{l}\text { Technology context, organization context, } \\
\text { environment context. }\end{array}$ \\
\hline Model of PC Utilization (MPCU) & 1991 & Thompson & $\begin{array}{l}\text { Job-fit, Complexity, Long-term Consequences, } \\
\text { Affect Towards Use, Social Factors, Facilitating } \\
\text { Conditions }\end{array}$ \\
\hline Motivational Model (MM) & 1992 & Davis & Extrinsic Motivation, Intrinsic Motivation \\
\hline $\begin{array}{c}\text { Information System Success } \\
\text { Model (ISSM) }\end{array}$ & 1992 & $\begin{array}{l}\text { DeLone \& } \\
\text { McLean }\end{array}$ & $\begin{array}{l}\text { System Quality, Information Quality, USE, User } \\
\text { Satisfaction, Individual Impact and Organizational } \\
\text { Impact }\end{array}$ \\
\hline $\begin{array}{l}\text { Combined TAM and TPB } \\
\text { (C-TAM-TPB) }\end{array}$ & 1995 & $\begin{array}{l}\text { Taylor \& } \\
\text { Todd }\end{array}$ & $\begin{array}{l}\text { Attitude Toward Behavior, Subjective Norm, } \\
\text { Perceived Behavioral Control, Perceived Usefulness }\end{array}$ \\
\hline $\begin{array}{l}\text { Unified Theory of Acceptance } \\
\text { and Use of Technology (UTAUT) }\end{array}$ & 2003 & $\begin{array}{l}\text { Venkatesh et } \\
\text { al }\end{array}$ & $\begin{array}{l}\text { Performance Expectancy, Effort Expectancy, Social } \\
\text { Influence Facilitating Condition }\end{array}$ \\
\hline $\begin{array}{l}\text { Fit Between Individuals, Task } \\
\text { and Technology (FITT) }\end{array}$ & 2006 & $\begin{array}{l}\text { Ammenwert } \\
\mathrm{h} \text { et al }\end{array}$ & $\begin{array}{l}\text { Task-Technology, Technology-Individual, } \\
\text { Individual-Task }\end{array}$ \\
\hline $\begin{array}{l}\text { Mobile Services Acceptance } \\
\text { Model (MSAM) }\end{array}$ & 2014 & Gaoa et al & $\begin{array}{l}\text { Trust, Context, Personal Initiatives and } \\
\text { Characteristics, Perceived Usefulness, Perceived } \\
\text { Ease of Use. }\end{array}$ \\
\hline
\end{tabular}

\subsection{E-Government Health Application Adoption Studies}

A study by Bennani and Oumlil in 2014 was conducted to study nurses' acceptance of e-health adoption in Morocco using the UTAUT model. Since 2001, the Moroccan government has shown interest in reforming the country's health-care system to improve performance and satisfy the public's demand for health care. Therefore, the government established a project to finance and manage the health sector and provide support to health professionals so they can improve the quality and efficiency of medical services. The main goal of this project was the deployment of HIS. Bennani and Oumlil (2014) studied factors influencing nurses' acceptance of this technology through a reduced version of the UTAUT model where the FC construct is a moderating variable and actual use is excluded. The TR construct is added to the remaining constructs PE, EE, and SI to predict the nurses' intention to use HIS. The study's scope is concerned with nurses working in both public and private organizations in Agadir city. Questionnaires targeted 200 nurses. Results showed that the proposal mode was useful in explaining the nurses' acceptance of HIS adoption. Two factors showed notable influence on acceptance, SI and TR (Bennani \& Oumlil, 2014).

Another study was conducted in 2016 by Gajanayake and colleagues to study an empirical model on the acceptance of accountable-eHealth (AeH) systems by health-care professionals in Australia. The AeH systems "are a new genre of E-Health systems designed to manage information privacy concerns that hinder the proliferation of E-Health" (Gajanayake et al., 2016). The study aimed to measure university students' (who were studying medicine, nursing, or other health-related courses) attitudes toward AeH systems. The proposed model was a modified version of UTAUT, where some amendments were made to fit the Australian health-care context. FC and SI factors were excluded, and the following constructs were added: Self-efficacy (SE), Anxiety (ANX), ATT, PE, EE, information governance (IG), information control (IC), and information accountability (IA). The model also included age, gender, computer literacy, academic year, level of study, and study discipline for the moderating variables. An online questionnaire survey was conducted to collect data from three educational institutions in Queensland, Australia. A total of 334 responses were received from the three participating institutions. The results showed that the proposed model was capable of predicting $47.3 \%$ of future health-care professionals' attitude and intention toward the AeH systems. The study also revealed the significant impact of the following moderating variables on the research model: age, gender, study discipline, study year, and the level of study (Gajanayake et al., 2016).

Moreover, a study by Hoque et al. (2017) aimed to improve health-care services in developing countries and to investigate the factors for e-health adoption in Bangladesh. In this context, a model was proposed based on TAM to determine patients' BI toward e-health. TAM was modified according to the e-health context in Bangladesh in 
which three measures were added to the TAM constructs: TR, privacy, and gender. The study targeted 318 physicians who work at private and public hospitals. The analysis showed that TR, PU, and PEOU directly affect physicians' decision to use EHRs. In addition, there was no significant relationship between privacy and the use of e-health in Bangladesh, based on the fact that people in Bangladesh are not concerned with privacy and disclosure of information to other parties. Gender significantly influenced the ITU e-health in the local context. Gender differences affected TR and influenced behavior, revealing that the effects of PU and PEOU on BI are moderated by gender. This study confirmed that PU, PEOU, and TR are vital for adopting e-health in Bangladesh (Hoque et al., 2017).

Alhashmi et al. (2019) explored the critical success factors for implementing artificial intelligence (AI) projects in Dubai, United Arab Emirates (UAE) health sector. AI has been used to help physicians and medical professionals make medical recommendations to patients based on patients' medical needs and status. AI is also utilized to provide early predictions for some diseases. The study proposed an extended TAM where the impact of five factors was tested on TAM constructs. These factors are managerial factors (MF), organizational factors (OF), operational factors (PF), strategic factors (SF), and IT infrastructure factors (IF). The study targeted employees working in the health and IT sectors in the UAE. As a result of the study, MF, OF, PF, and IF were affected positively with PEOU and PU. SF had a negative effect on PEOU and a positive effect on PU (Alhashmi et al., 2019).

AlBar and Hoque (2019) conducted a study from patients' perspective to understand patients' perceptions toward e-health services in SA. The paper aimed to validate a proposed model that integrated constructs from the TAM and TPB. The study targeted patients at numerous private and public hospitals in SA. The study revealed that PEOU and PU have a significant influence on patients' ATT. Moreover, ATT and SN have a positive and significant influence on patients' BI. Contrarily, PBC showed no significant impact on patients' BI to use e-health in SA.

A recent study by Yusif et al. (2020) explored the adoption readiness of the new HIT of the Komfo Anokye Teaching Hospital (KATH) in Ghana. The study utilized the TOE framework to evaluate the organization's readiness for new technology. The readiness assessment factors included technology readiness, operational resource readiness, organizational and cultural readiness, regulatory and policy readiness, and core readiness. The results verified the model in which the readiness assessment factors could explain 97\% of HIT/e-health adoption readiness at KATH (Yusif et al., 2020). Refer to Table 3 for a summary of all the studies mentioned above.

Table 3. Studies' Summary

\begin{tabular}{|l|l|l|l|l|l|l|}
\hline $\begin{array}{l}\text { Author/Ye } \\
\text { ar }\end{array}$ & Objectives & Country & Methodology & Model & $\begin{array}{l}\text { Sample } \\
\text { Size }\end{array}$ & Key Findings \\
\hline $\begin{array}{l}\text { Bennani et } \\
\text { al., } 2014\end{array}$ & $\begin{array}{l}\text { Identifying } \\
\text { factors } \\
\text { influencing the } \\
\text { acceptance of } \\
\text { HIS by nurses } \\
\text { in Morocco. }\end{array}$ & Morocco & Quantitative & $\begin{array}{l}\text { Modified } \\
\text { UTAUT } \\
\text { model }\end{array}$ & 200 nurses & $\begin{array}{l}\text { Reduced version of UTAUT } \\
\text { and Trust construct showed } \\
\text { their significance in } \\
\text { determining the factors } \\
\text { influencing nurses' acceptance. } \\
\text { SI and TR were the most } \\
\text { significant factors }\end{array}$ \\
\hline $\begin{array}{l}\text { Gajanayake } \\
\text { et al,, 2016 }\end{array}$ & $\begin{array}{l}\text { To study the } \\
\text { acceptance of } \\
\text { Accountable-E- } \\
\text { Health (AeH) } \\
\text { systems in } \\
\text { healthcare }\end{array}$ & Australia & $\begin{array}{l}\text { Quantitative } \\
\text { and } \\
\text { qualitative }\end{array}$ & $\begin{array}{l}\text { Modified } \\
\text { UTATU } \\
\text { model }\end{array}$ & $\begin{array}{l}334 \\
\text { students } \\
\text { (future } \\
\text { healthcare } \\
\text { profession } \\
\text { als) }\end{array}$ & $\begin{array}{l}\text { The proposed model could } \\
\text { explain 47.3\% of future } \\
\text { healthcare professionals' } \\
\text { attitude towards the AeH } \\
\text { systems. } \\
\text { The moderating variables: age, } \\
\text { gender, study discipline, study } \\
\text { year and the level of study } \\
\text { showed a significant impact on } \\
\text { AeH acceptance. }\end{array}$ \\
\hline $\begin{array}{l}\text { Hoque et } \\
\text { al., 2016 }\end{array}$ & $\begin{array}{l}\text { Identifying } \\
\text { factors } \\
\text { influencing the } \\
\text { acceptance of } \\
\text { E-Health in } \\
\text { developing } \\
\text { countries. }\end{array}$ & $\begin{array}{l}\text { Banglades } \\
\text { h }\end{array}$ & Quantitative & $\begin{array}{l}\text { Modified } \\
\text { TAM }\end{array}$ & $\begin{array}{l}318 \\
\text { physicians }\end{array}$ & $\begin{array}{l}\text { affect physicians' decision to } \\
\text { use E-Health system. } \\
\text { Unlike gender, no significant } \\
\text { relationship found between } \\
\text { privacy, and the use of } \\
\text { E-Health }\end{array}$ \\
\hline
\end{tabular}




\begin{tabular}{|c|c|c|c|c|c|c|}
\hline $\begin{array}{l}\text { Alhashmi et } \\
\text { al.,2019 }\end{array}$ & $\begin{array}{l}\text { Explore the } \\
\text { critical success } \\
\text { factors for } \\
\text { implementing } \\
\text { AI projects } \\
\text { health sector }\end{array}$ & UAE & Quantitative & TAM & $\begin{array}{l}53 \\
\text { employees } \\
\text { working } \\
\text { in the } \\
\text { health and } \\
\text { IT sectors }\end{array}$ & $\begin{array}{l}\text { The relation between the most } \\
\text { factors and variables are } \\
\text { positive on PEOU and PU for } \\
\text { implementing AI. } \\
\text { Managerial factors (MF), } \\
\text { organizational factor (OF), } \\
\text { operational factor (OF), and } \\
\text { infrastructure factor (IF) were } \\
\text { affected positively with PEOU } \\
\text { and PU. } \\
\text { SF has a negative effect on } \\
\text { PEOU and a positive one on } \\
\text { PU. }\end{array}$ \\
\hline $\begin{array}{l}\text { AlBar \& } \\
\text { Hoque, } \\
(2019)\end{array}$ & $\begin{array}{l}\text { Explore } \\
\text { patients' } \\
\text { acceptance and } \\
\text { use of e-health } \\
\text { in Saudi Arabia }\end{array}$ & SA & Quantitative & $\begin{array}{l}\text { TAM and } \\
\text { TPB } \\
\text { models }\end{array}$ & $\begin{array}{l}\text { Not } \\
\text { specified }\end{array}$ & $\begin{array}{l}\text { PEOU and PU has a significant } \\
\text { influence on patients' ATT. } \\
\text { ATT and SN have significant } \\
\text { influence on patients' BI. } \\
\text { PBC showed no significant } \\
\text { impact on patient's BI to use } \\
\text { e-health in SA. }\end{array}$ \\
\hline $\begin{array}{l}\text { Yusif et al., } \\
2020\end{array}$ & $\begin{array}{l}\text { Identify the HIT } \\
\text { adoption } \\
\text { readiness } \\
\text { factors. }\end{array}$ & Ghana & $\begin{array}{l}\text { Quantitative } \\
\text { and } \\
\text { qualitative }\end{array}$ & TOE & $\begin{array}{l}298 \\
\text { Responde } \\
\text { nts }\end{array}$ & $\begin{array}{l}\text { The proposed model includes } \\
\text { the following factors: } \\
\text { technology readiness; } \\
\text { operational resource readiness; } \\
\text { organizational readiness; } \\
\text { regulatory and policy } \\
\text { readiness; and core readiness. } \\
\text { The model could explain } 97 \% \\
\text { of HIT/ eHealth adoption } \\
\text { readiness }\end{array}$ \\
\hline
\end{tabular}

\section{Method}

This part of the research paper outlines the proposal for a new model. It includes the research method, hypotheses, and instrument used to collect data. The proposed model was developed and applied to study the factors influencing the adoption and acceptance of e-government health applications (i.e., Mawid, Tetamman, Tawakkalna, and Tabaud) launched and used in SA during the COVID-19 pandemic.

The model proposed in this research aimed to examine the main influencing factors that impact the adoption of e-government health applications. The study authors developed the model by utilizing seven constructs from four models to serve the study's purpose. The models are UTAUT, TAM, MSAM, and ISSM. The seven constructs are SI and FC from UTAUT; PEOU, PU, and ATT from TAM; IQ from ISSM; and TR from MSAM. Figure 1 provides the theoretical framework.

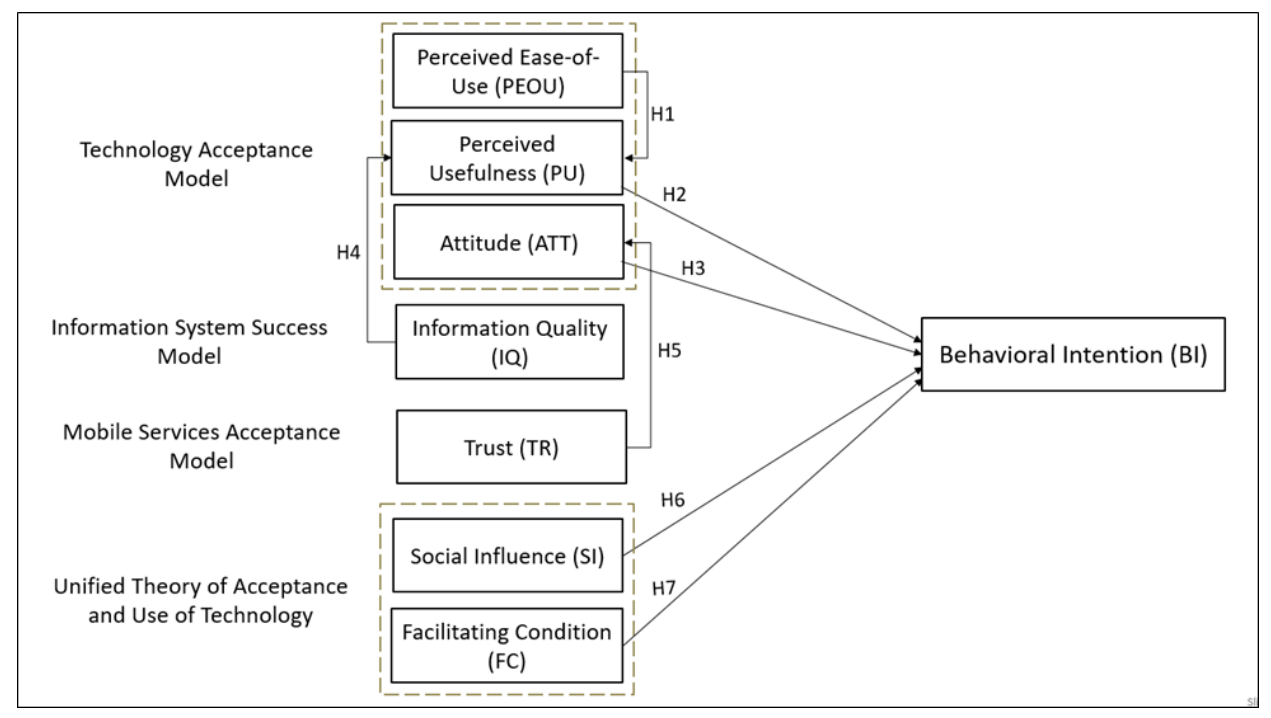

Figure 1. Theoretical Framework 


\subsection{Hypotheses}

Research has suggested that different models and their factors influence the adoption of e-government health applications: SI and FC from UTAUT; PEOU, PU, and ATT from TAM; IQ from ISSM; and TR from MSAM.

\subsubsection{TAM Hypotheses}

After evaluating multiple TAM meta-analysis studies conducted between 2003 and 2010, Mardiana et al. (2015) found that the best predictor of BI is PU. Empirical studies have shown that PU is a powerful indicator of intention to use. Masrom (2007) and Venkatesh and Morris (2003) asserted that PU has a positive and essential effect on BI in using technology.

Moreover, past studies have confirmed the positive impact of ATT on BI in a health-care technology context (e.g., Alsharo et al., 2019; Dutta et al., 2018). Therefore, we hypothesize the following:

H1: PEOU will have a positive influence on PU to use e-government health applications.

H2: PU will have a positive influence on BI to use e-government health applications.

H3: ATT will have a positive influence on BI to use e-government health applications.

\subsubsection{ISSM Hypotheses}

For measuring IT success, the ISSM is one of the most cited models in research papers and it creates a comprehensive taxonomy for evaluating the factors that influence IS users (Yakubu \& Dasuki, 2018). The study by Ahn et al. (2007) indicated that IQ has a positive influence on user perception of PU. According to Chen and Hsiao (2012), IQ is a key factor affecting PU, which significantly affects HIS acceptance. Moreover, Lin (2007) argued that IQ is a valuable predictor for PU. Typical measurement items for IQ output include comprehension, accuracy, and relevance in current situations. Accordingly, we hypothesize as follows:

H4: IQ will have a positive influence on PU to use e-government health applications.

\subsubsection{MSAM Hypotheses}

Researchers have applied the MSAM in studies in various fields, such as education and health, where new mobile technology is adopted (Altun, 2018). TR is a critical variable affecting the adoption of e-government services (Gadabu, 2020). According to Alsajjan and Dennis (2010), TR positively influences ATT. Moreover, Amaro and Duarte (2015), and Ashraf et al. (2014) found a significant path from TR to ATT. Therefore, we hypothesize the following:

H5: TR will have a positive influence on ATT to use e-government health applications.

\subsubsection{UTAUT Hypotheses}

UTAUT is known as one of the most cited models in research papers that study user acceptance. The model is supported and applicable in different contexts within health informatics studies (Cohen et al., 2013). SI measure was rejected in some studies, for example, Cohen et al. (2013), who stated that SI does not show enough influence on technology acceptance in the presence of other factors. Contrarily, a study by Hoque and Sorwar (2017) stated that SI often influences technology adoption. Other studies stated that technology adoption relies heavily on SI as well as the individual's belief towards technology (Hsu and Lu, 2004). FC, has shown its positive influence on the acceptance of technology in various studies. Orruño et al. (2011) identified FC as the most critical factor influencing acceptance. Another study (Crosson et al., 2011) showed that inadequate technical support and limited on-site technology resources are considered barriers to adopt e-prescribing systems. Moreover, Kaushal et al. (2010) found that the availability of technical support is essential to the success of using e-prescribing. Based on this, we hypothesize the following:

H6: SI will have a positive influence on BI to use e-government health applications.

H7: FC will have a positive influence on BI to use e-government health applications.

The study authors applied the constructs of UTAUT, TAM, ISSM, and MSAM according to this study's scope to implement the hypotheses. PEOU is the degree to which users believe that using health applications will be free of effort. PU is whether users believe that using health applications will improve general health effectiveness. ATT is the degree of the need to develop positive attitudes toward e-government health applications to ensure users' acceptance and continuity in using them. SI is the degree to which others' opinions influence the citizens and residents to use health applications. FC measures the extent to which the $\mathrm{MOH}$ provides health care and medical aids to users to monitor the movement of people infected with COVID-19 and limit their mixing with others. IQ involves users' satisfaction regarding accuracy, relevance, understandability, and information 
completeness when they use health applications. TR is defined as users' feelings to trust MOH for security, privacy, and personal data confidentiality.

To test the proposed model, we used a quantitative research method, including surveying the public in SA. The survey items were derived from seven constructs used in the proposed model. We reviewed previous studies that utilized the same constructs and modified them to fit the study scope. Table 4 shows the survey's items.

Table 4. Survey Items

\begin{tabular}{|c|c|c|}
\hline Constructs & Survey Items & Reference \\
\hline $\begin{array}{l}\text { Perceived Ease of } \\
\text { Use (PEOU) }\end{array}$ & $\begin{array}{l}\text { PEOU1: E-Government health applications (Mawid, Tetamman, Tawakkalna, } \\
\text { Tabaud) Launched during COVID-19 are very clear and easy to navigate. } \\
\text { PEOU2: I find it easy to use E-Government health applications (Mawid, Tetamman, } \\
\text { Tawakkalna, Tabaud) features, for example booking an appointment through Mawid } \\
\text { application; issue a movement permit during the curfew using Tawakkalna } \\
\text { application. } \\
\text { PEOU3: Using E-Government health applications (Mawid, Tetamman, Tawakkalna, } \\
\text { and Tabaud) is more flexible than the traditional way. }\end{array}$ & $\begin{array}{l}\text { (Davis 1989; } \\
\text { Davis et al. } \\
\text { 1989). } \\
\text { (Weng et al., } \\
\text { 2018). }\end{array}$ \\
\hline $\begin{array}{l}\text { Perceived } \\
\text { Usefulness (PU) }\end{array}$ & $\begin{array}{l}\text { PU1: I find it useful to use E-Government health applications (Mawid, Tetamman, } \\
\text { Tawakkalna, Tabaud) in providing faster flow of information such as showing users' } \\
\text { health conditions using Tataman; and to notify those who are in contact with people } \\
\text { infected with the coronavirus Tawakkalna. } \\
\text { PU2: I find E-Government health applications (Mawid, Tetamman, Tawakkalna, and } \\
\text { Tabaud) saves my time. } \\
\text { PU3: I find the E-Government health applications (Mawid, Tetamman, Tawakkalna, } \\
\text { and Tabaud) useful during COVID-19. } \\
\text { PU4: E-Government health applications (Mawid, Tetamman, Tawakkalna, and } \\
\text { Tabaud) enables me to perform transactions that are not close to my location. }\end{array}$ & $\begin{array}{l}\text { (Davis, 1989). } \\
\text { (Davis et al. } \\
\text { 1989). } \\
\text { (Weng et al., } \\
\text { 2018). } \\
\text { (Almuraqab, } \\
\text { 2017). }\end{array}$ \\
\hline Trust (TR) & $\begin{array}{l}\text { TR1: I feel confident about my personal data while using the E-Government health } \\
\text { applications (Mawid, Tetamman, Tawakkalna, and Tabaud). } \\
\text { TR2: I trust using mobile applications for government health transactions. } \\
\text { TR3: I feel confident that the E-Government health applications (Mawid, Tetamman, } \\
\text { Tawakkalna, and Tabaud) information are reliable. }\end{array}$ & $\begin{array}{c}\text { (Adellia \& } \\
\text { Prasetio ,2016). } \\
\text { (Eid et } \\
\text { al. ,2020). }\end{array}$ \\
\hline $\begin{array}{l}\text { Facilitating } \\
\text { Conditions (FC) }\end{array}$ & $\begin{array}{l}\text { FC1: Enough materials explaining how to use E-Government health applications } \\
\text { (Mawid, Tetamman, Tawakkalna, and Tabaud) are provided. } \\
\text { FC2: If I face any technical issue in using E-Government health applications } \\
\text { (Mawid, Tetamman, Tawakkalna, Tabaud), technical support is available to assist me. } \\
\text { FC3: I find E-Government health applications (Mawid, Tetamman, Tawakkalna, and } \\
\text { Tabaud) always up and running perfectly when I need to use them. }\end{array}$ & $\begin{array}{l}\text { (Venkateshet } \\
\text { al., 2003). } \\
\text { (Almajali et } \\
\text { al.,2015). } \\
\text { (Williamson \& } \\
\text { Parolin, 2013). }\end{array}$ \\
\hline $\begin{array}{l}\text { Information } \\
\text { Quality (IQ) }\end{array}$ & $\begin{array}{l}\text { IQ1: I feel E-Government health applications (Mawid, Tetamman, Tawakkalna, and } \\
\text { Tabaud) provide accurate information. } \\
\text { IQ2: I feel E-Government health applications (Mawid, Tetamman, Tawakkalna, and } \\
\text { Tabaud) Provide timely and up-to-date information. } \\
\text { IQ3: I find E-Government health applications (Mawid, Tetamman, Tawakkalna, and } \\
\text { Tabaud) provide relevant and precise information about the current situation. }\end{array}$ & $\begin{array}{c}\text { (Adellia \& } \\
\text { Prasetio ,2016). } \\
\text { (Zulfan, 2018). }\end{array}$ \\
\hline Attitude (ATT) & $\begin{array}{l}\text { ATT1: Using E-Government health applications (Mawid, Tetamman, Tawakkalna, } \\
\text { and Tabaud) during COVID-19 pandemic is a good idea. } \\
\text { ATT2: Using E-Government health applications (Mawid, Tetamman, Tawakkalna, } \\
\text { and Tabaud) to reach health information is valuable during COVID-19 pandemic. } \\
\text { ATT3: I am satisfied with using E-Government health applications (Mawid, } \\
\text { Tetamman, Tawakkalna, and Tabaud). }\end{array}$ & $\begin{array}{c}\text { (Weng et al., } \\
\text { 2018). } \\
\text { (Verkijika \& } \\
\text { Wet, 2018). } \\
\text { (Al-Aboudi et } \\
\text { al., 2016). }\end{array}$ \\
\hline $\begin{array}{l}\text { Social Influence } \\
\text { (SI) }\end{array}$ & $\begin{array}{l}\text { SI1: People who influence my behavior think I should use E-Government health } \\
\text { applications (Mawid, Tetamman, Tawakkalna, and Tabaud) launched during } \\
\text { COVID-19 pandemic. } \\
\text { SI2: The government has supported the use of the health applications (Mawid, } \\
\text { Tetamman, Tawakkalna, and Tabaud). } \\
\text { SI3: People whose opinions I value would prefer me to use E-Government services. }\end{array}$ & $\begin{array}{l}\text { (Venkatesh et } \\
\text { al., 2003) } \\
\text { (Tran et al., } \\
\text { 2019). } \\
\text { (Verkijika \& } \\
\text { Wet, 2018). }\end{array}$ \\
\hline $\begin{array}{l}\text { Behavioral } \\
\text { Intention (BI) }\end{array}$ & $\begin{array}{l}\text { BI1: I intend to use E-Government health applications (Mawid, Tetamman, } \\
\text { Tawakkalna, and Tabaud) even if they are not mandatory. } \\
\text { BI2: If I am suspecting that I have COVID-19 symptoms, I will use E-Government } \\
\text { health applications (Mawid, Tetamman, Tawakkalna, and Tabaud). } \\
\text { BI3: I plan to use the E-Government health applications (Mawid, Tetamman, } \\
\text { Tawakkalna, and Tabaud) in future. } \\
\text { BI4: I recommend others to use E-Government health applications (Mawid, } \\
\text { Tetamman, Tawakkalna, and Tabaud). }\end{array}$ & $\begin{array}{l}\text { (Davis, 1989). } \\
\text { (Böhm et al., } \\
\text { 2009). } \\
\text { (Kuo \& } \\
\text { Yen, 2009). } \\
\text { (Saprikis et al., } \\
\text { 2018). }\end{array}$ \\
\hline
\end{tabular}




\subsection{Study Setting and Participants}

The survey items were measured using a five-point Likert scale to measure the public's level of agreement, from 1 , strongly disagree, to 5 , strongly agree. The survey also includes demographic questions regarding age and gender. The survey was distributed online in two languages, English and Arabic. The participants were selected randomly based on two criteria: age above 18 years old and experienced in using e-government health applications Mawid, Tetamman, Tawakkalna, and Tabaud.

\subsection{Data Collection}

This study's data were collected by publicly sending a survey through social media in SA via WhatsApp, Twitter, Telegram, and Snapchat with a short description of the study in Arabic and English. After eliminating incomplete responses, 785 valid responses were identified out of 889 . Thus, 785 questionnaires were subjected to further analysis.

\subsection{Demographic Items}

Some demographic items, such as gender and age, were included in the survey. Table 5 shows the demographic percentages. The sample consisted of $45 \%$ males (356) and 55\% (429) females, 364 participants aged between 18 and 29, 186 participants aged between 30 and 39, 147 participants aged between 40 and 49, 71 participants aged between 50 and 59, and 17 participants aged 60 and above.

Table 5. Demographic Sample

\begin{tabular}{ccc}
\hline Demographic Category & Frequency & Valid Percentage \\
\hline Gender & 429 & \\
Female & 356 & $55 \%$ \\
Male & & $45 \%$ \\
\hline Age & 364 & $46 \%$ \\
$18-29$ & 186 & $24 \%$ \\
$30-39$ & 147 & $19 \%$ \\
$40-49$ & 71 & $9 \%$ \\
$50-59$ & 17 & $2 \%$ \\
$60+$ & & \\
\hline
\end{tabular}

\section{Analysis and Results}

The study authors used the partial least-squares (PLS) method to test each construct's reliability and validity in the proposed model. Based on Hoque et al. (2017), PLS "is a statistical analysis technique based on the structural equation model (SEM)." SmartPLS Version 3.0 and the two-step analysis approach were used to analyze the survey data (Please refer to Figure 2). The proposed theoretical model consists of eight constructs: PEOU, PU, ATT, IQ, TR, FC, IS, and BI. As per measurement items, a total of 26 items for latent constructs in the proposed model were developed from previous studies and modified for the e-government health applications in SA. In this section of the research paper, two models are assessed, the measurement model and the structural model.

\subsection{Test of the Measurement Model}

The measurement model, which is referred to as the outer model in PLS-SEM, describes the relationships between the constructs and their indicator variables; the relationships flow in two directions. Either the relationship goes from the construct to the indicators (reflective) or from the indicators to the construct (formative; Hair et al., 2016). To assess the reflective measures, convergent and discriminant validity analyses were conducted, where convergent validity is "the extent to which a measure correlates positively with others" (Hair et al., 2016). Contrarily, discriminant validity is "the extent to which a construct is truly distinct from other constructs by empirical standards" (Hair et al., 2016). Convergent validity was tested using three approaches: factor loadings, composite reliability (CR), and average variance extracted (AVE). All constructs were modeled in the reflective mode, except FC and TR, which were modeled in the formative mode. According to Table 6, all reflective items had factor loadings above 0.7 , indicating sufficient indicator reliability levels (Carmines \& Zeller, 1979). CR values ranged from 0.892 to 0.936 . Therefore, CR exceeded the recommended value of 0.7 , which is regarded as satisfactory (Fornell \& Larcker, 1981; Nunnally, 1978). The AVE was in the range of 0.694 to 0.83 , exceeding the recommended value of 0.5 and indicating that the construct explains more than half of its indicators' variance (Hair et al., 2017). Consequently, the measurement model has qualified indicator reliability, internal consistency reliability, and convergent validity. 
After testing convergent validity, discriminant validity was tested, as shown in Table 7 . To evaluate the discriminant validity of reflective indicators, cross-loading is suggested as the primary measure, which means that an indicator's loadings with its associated latent construct should be higher than its loadings with all the remaining constructs (Hair et al., 2011; Ali et al., 2018). All the indicators showed a qualified discriminant validity via the cross-loadings evaluation because constructs shared more variance with their items than with other constructs in the model. The evaluation indicated that the model has good convergent and discriminant validity.

For the formative measurement model, as shown in Table 8, the multicollinearity test was examined by the variance inflation factor (VIF). All items' VIFs were within the acceptable range, which is below 5. Thus, no items were deleted. Furthermore, the highest VIF calculated was 2.385 and thus was below the upper border recommended by Diamantopoulos and Siguaw (2006).

Table 6. Reflective Measurement Model

\begin{tabular}{ccccc}
\hline Construct & Item & Loading & CR & AVE \\
\hline Perceived Ease of Use & PEOU1 & 0.837 & 0.892 & 0.733 \\
& PEOU2 & 0.878 & & \\
& PEOU3 & 0.853 & & \\
\hline Perceived Usefulness & PU1 & 0.794 & 0.901 & 0.694 \\
& PU2 & 0.868 & & \\
& PU3 & 0.855 & & \\
& PU4 & 0.814 & & 0.83 \\
& IQ1 & 0.904 & 0.936 & \\
Information Quality & IQ2 & 0.919 & & \\
& IQ3 & 0.910 & & \\
& ATT1 & 0.885 & 0.894 & \\
\hline Attitude & ATT2 & 0.839 & & \\
& ATT3 & 0.877 & & \\
& SI1 & 0.854 & 0.895 & \\
\hline Social Influence & SI2 & 0.830 & & \\
& SI3 & 0.894 & & \\
& BI1 & 0.840 & 0.902 & \\
\hline Behavioral Intention & BI2 & 0.811 & & \\
& BI3 & 0.844 & & \\
& BI4 & 0.846 & & \\
\hline
\end{tabular}

Loadings, AVE, CR belong to the reflective measurement model.

$\mathrm{CR}=$ Composite reliability, $\mathrm{AVE}=$ Average variance extracted

All item loading > 0.7 indicate indicator reliability. (Carmines \& Zeller, 1979)

All AVE > 0.5 indicates convergent reliability. (Hair et al., 2017).

All CR > 0.7 Indicate internal consistency. (Nunnally, 1978)

Table 7. Discriminant validity: Item Cross Loading

\begin{tabular}{ccccccc}
\hline & PEOU & PU & \multicolumn{1}{c}{ IQ } & ATT & SI & BI \\
\hline PEOU1 & $\mathbf{0 . 8 3 7}$ & 0.626 & 0.587 & 0.584 & 0.561 & 0.603 \\
PEOU2 & $\mathbf{0 . 8 7 8}$ & 0.672 & 0.624 & 0.637 & 0.615 & 0.601 \\
PEOU3 & $\mathbf{0 . 8 5 3}$ & 0.700 & 0.587 & 0.657 & 0.589 & 0.630 \\
PU1 & 0.676 & $\mathbf{0 . 7 9 5}$ & 0.670 & 0.626 & 0.651 & 0.601 \\
PU2 & 0.666 & $\mathbf{0 . 8 6 8}$ & 0.587 & 0.656 & 0.630 & 0.657 \\
PU3 & 0.636 & $\mathbf{0 . 8 5 5}$ & 0.584 & 0.696 & 0.639 & 0.627 \\
PU4 & 0.615 & $\mathbf{0 . 8 1 4}$ & 0.556 & 0.617 & 0.605 & 0.579 \\
IQ1 & 0.603 & 0.642 & $\mathbf{0 . 9 0 4}$ & 0.630 & 0.683 & 0.648 \\
IQ2 & 0.656 & 0.672 & $\mathbf{0 . 9 1 9}$ & 0.705 & 0.723 & 0.670 \\
IQ3 & 0.654 & 0.656 & $\mathbf{0 . 9 1 0}$ & 0.676 & 0.676 & 0.651 \\
ATT1 & 0.592 & 0.689 & 0.604 & $\mathbf{0 . 8 5 8}$ & 0.666 & 0.634 \\
ATT2 & 0.571 & 0.623 & 0.611 & $\mathbf{0 . 8 3 9}$ & 0.644 & 0.604 \\
ATT3 & 0.714 & 0.692 & 0.676 & $\mathbf{0 . 8 7 7}$ & 0.722 & 0.714 \\
SI1 & 0.529 & 0.591 & 0.637 & 0.616 & $\mathbf{0 . 8 5 4}$ & 0.606 \\
SI2 & 0.627 & 0.698 & 0.647 & 0.761 & $\mathbf{0 . 8 3 0}$ & 0.681 \\
& & & 14 & & &
\end{tabular}




\begin{tabular}{lllllll} 
SI3 & 0.610 & 0.659 & 0.679 & 0.656 & $\mathbf{0 . 8 9 4}$ & 0.687 \\
BI1 & 0.585 & 0.607 & 0.623 & 0.615 & 0.670 & $\mathbf{0 . 8 4 0}$ \\
BI2 & 0.601 & 0.620 & 0.566 & 0.621 & 0.605 & $\mathbf{0 . 8 1 1}$ \\
BI3 & 0.562 & 0.569 & 0.590 & 0.592 & 0.623 & $\mathbf{0 . 8 4 4}$ \\
BI4 & 0.637 & 0.674 & 0.626 & 0.708 & 0.665 & $\mathbf{0 . 8 4 6}$ \\
\hline
\end{tabular}

Table 8. Formative Measurement Model

\begin{tabular}{ccc}
\hline Construct & Item & VIF \\
\hline Facilitating Conditions & FC1 & 1.919 \\
& FC2 & 2.163 \\
& FC3 & 1.903 \\
Trust & TR1 & 2.199 \\
& TR2 & 2.385 \\
& TR3 & 2.277 \\
\hline
\end{tabular}

$\mathrm{VIF}=$ variance inflation factor

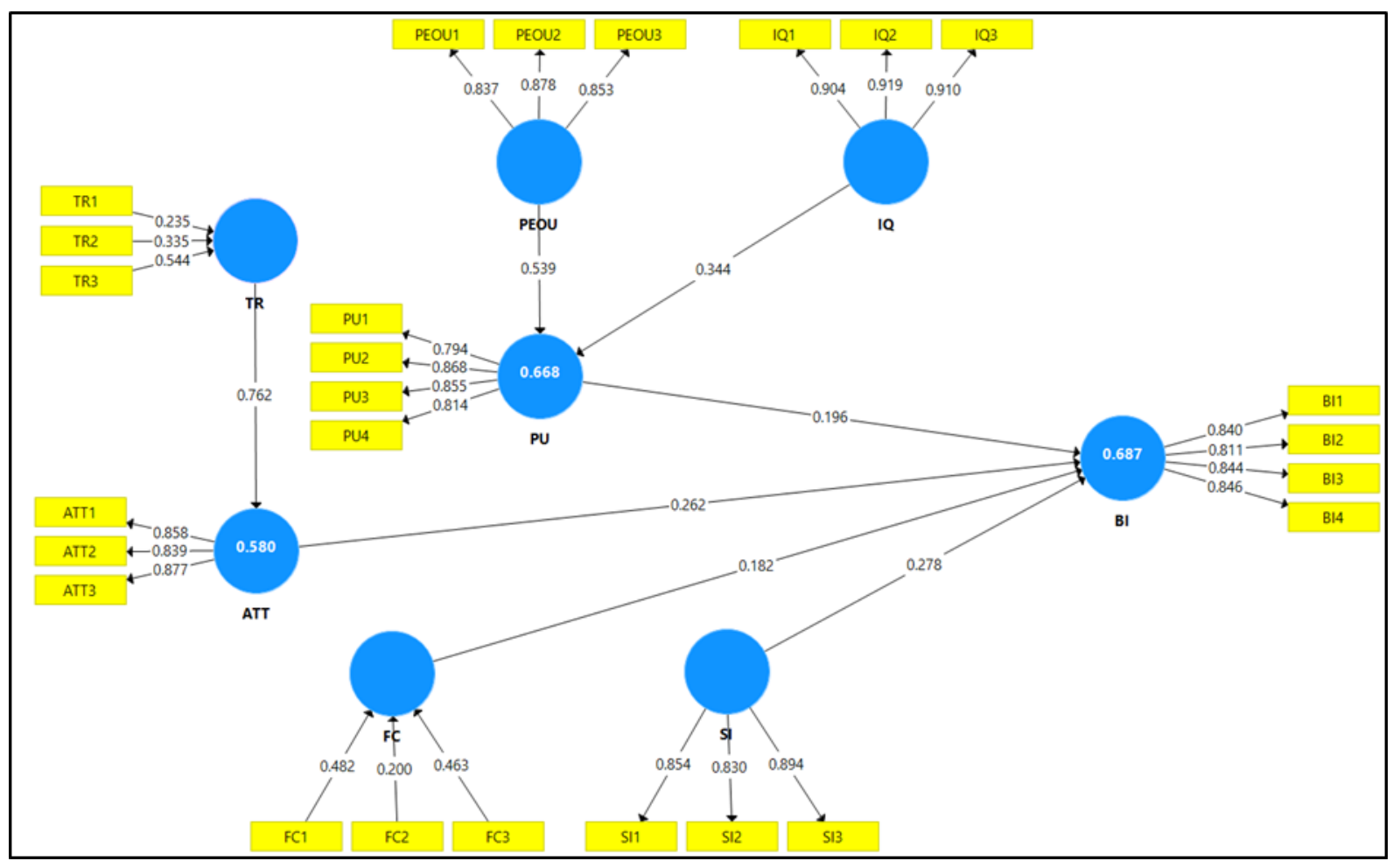

Figure 2. SmartPLS Output of the Measurement Model

4.2 Test of the Structural Model

Table 9. Hypothesis Testing

\begin{tabular}{ccccccc}
\hline Hyp & Description & $\begin{array}{c}\text { Path Coefficient } \\
(\boldsymbol{\beta})\end{array}$ & $\begin{array}{c}\text { Standard } \\
\text { Error }\end{array}$ & T-Value & $\begin{array}{c}\text { P- } \\
\text { Value }\end{array}$ & Decision \\
\hline H1 & PEOU -> PU & 0.539 & 0.039 & 13.697 & 0.000 & Supported \\
H2 & PU -> BI & 0.196 & 0.060 & 3.258 & 0.001 & Supported \\
H3 & ATT -> BI & 0.262 & 0.059 & 4.45 & 0.000 & Supported \\
H4 & IQ -> PU & 0.344 & 0.039 & 8.845 & 0.000 & Supported \\
H5 & TR -> ATT & 0.762 & 0.023 & 33.214 & 0.000 & Supported \\
H6 & SI -> BI & 0.278 & 0.059 & 4.707 & 0.000 & Supported \\
H7 & FC -> BI & 0.182 & 0.044 & 4.179 & 0.000 & Supported \\
\hline
\end{tabular}

In this paper, the study authors applied one test for the structural model, which is the hypothesis testing, based on the P-value. According to Table 9, all the hypotheses were supported (Please refer to Figure 3). For the first 
hypothesis, which aimed to test the PEOU that influences e-government health applications in SA, the results showed that PEOU positively affects the public's perceived usefulness to use e-government health applications ( $\beta=0.539, \mathrm{p}<0.000)$. Thus, $\mathrm{H1}$ was strongly supported.

The second hypothesis is PU's influence on e-government health applications in SA. The results showed that PU positively affects the public's intentions to use e-government health applications $(\beta=0.196, p<0.001)$. Thus, $\mathrm{H} 2$ was strongly supported.

The third hypothesis is the ATT that influences e-government health applications in SA (i.e., Mawid, Tetamman, Tawakkalna, and Tabaud). The results showed that ATT positively affects the public's intention to use e-government health applications $(\beta=0.262, \mathrm{p}<0.000)$. Thus, $\mathrm{H} 3$ was strongly supported.

The fourth hypothesis is IQ that influences e-government health applications in SA. The results showed that IQ positively affects the public's perceived usefulness to use e-government health applications $(\beta=0.344, p<$ 0.000). Thus, $\mathrm{H} 4$ was strongly supported.

The fifth hypothesis is TR that influences e-government health applications in SA. The results showed that TR positively affects the public's attitude to use e-government health applications $(\beta=0.762, \mathrm{p}<0.000)$. Thus, H5 was strongly supported.

The sixth hypothesis is SI that influences e-government health applications in SA. The results showed that SI positively affects the public's intention to use e-government health applications $(\beta=0.278, p<0.000)$. Thus, H6 was strongly supported.

The seventh and final hypothesis is FC that influences e-government health applications in SA. The results showed that FC positively affects the public's intention to use e-government health applications $(\beta=0.182, \mathrm{p}<$ 0.000). Thus, $\mathrm{H7}$ was strongly supported.

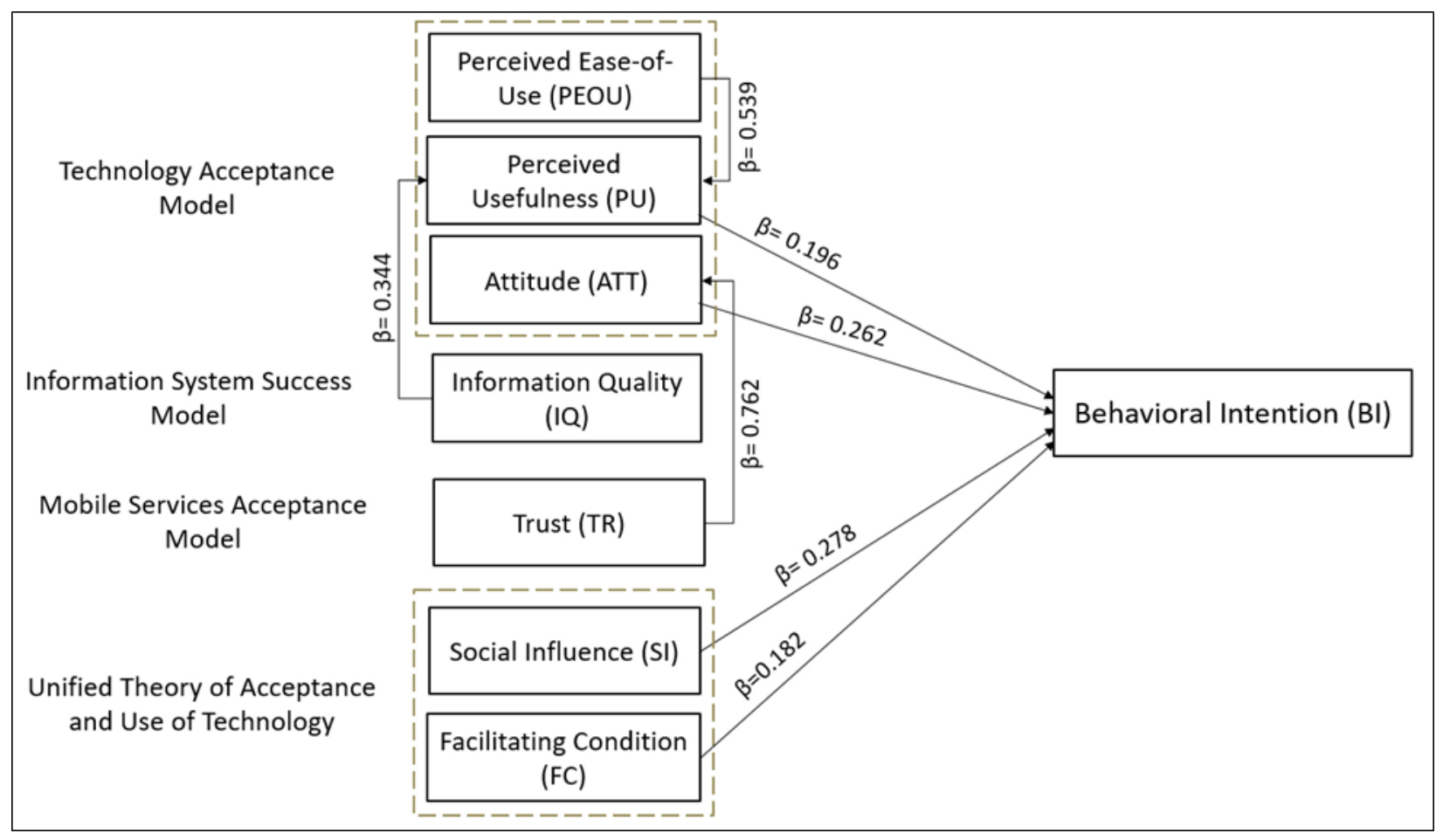

Figure 3. Results of the Structural Model

\section{Discussion}

This study explored the public's BI to use e-government health applications, which are Mawid, Tetamman, Tawakkalna, and Tabaud. It further examined the associations between the public's BI and the seven selected factors of PU, PEOU, ATT, SI, FC, TR, and IQ. Similar results in the literature verified the descriptive analysis of $\mathrm{BI}$ and the correlation analysis between BI and the variables mentioned earlier. The study results reveal that most of the public has a strong BI to use the e-government health applications launched during the COVID-19 
pandemic. The results of this study are consistent with Ajzen and Fishbein's theory (1975). They are incongruent with Davis's (1989) findings, which suggested that BI was a good predictor of actual computer usage. Based on the data analysis in the previous section, the results are as follows.

First, PU has a significant relationship with BI. If the e-government health applications are useful to the public and increase their learning outcomes, then their intentions to use the health applications will increase. The correlation analysis shows that BI has a strong and positive relationship with PU and PEOU. These findings are congruent with Aldosari (2012) study, which aimed to investigate the radiology users' acceptance of a picture archiving and communication system (PACS) in the radiology department at King Abdulaziz Medical City hospital in Riyadh, SA. Suffice it to say that past studies have confirmed the importance of TAM, PU, and PEOU in influencing the user's decision whether to accept or reject technology (Aldosari, 2012).

Second, PEOU has a significant relationship with PU. If the public perceives e-government health applications as easy to use and that they increase their learning outcomes, they will find those applications as useful. Hence, PEOU will influence their intention to use the technology. Previous studies have supported this direct relationship. For example, Or et al.'s (2011) study's analysis validated the PEOU and PU relationship in which patients' perceptions of consumer health information technologies' usefulness depended on the ease of use of such technology. Similary, a recent study by Bamufleh (2021), which investigates patient's intention to use electronic medical records (EMR) system, the results confirmed the positive effect of PEOU on PU.

Third, ATT has a significant relationship with BI. If the public has a positive ATT about providing and gathering their health information using e-government health applications, their intentions to use them will increase. The acceptance of clinical information systems among hospital medical staff was clarified in a study by Melas et al. (2011), which asserted that BI has a positive relation to ATT.

Fourth, IQ has a significant relationship with PU. Users will perceive e-government health applications as helpful and useful if the quality of health information generated is accurate, timely, up to date, precise, and relevant to the current situation. A study by Machdar (2019), which aimed to test the effect of IQ on PU, concluded that the quality of information positively affects PU.

Fifth, TR has a significant indirect relationship with BI through ATT. If the e-government health applications are reliable to the public and increase their satisfaction, their intentions to use the health applications will increase. A study by Al-Ajam and Nor (2013), which investigated the factors that influence BI to use internet banking, supported this relationship. They stated that user trust has an indirect influence on user BI if user attitude positively correlates with BI.

Sixth, SI has a significant relationship with BI, which means that other people influence the users of e-government health applications to use those applications. Many studies have supported this relationship. One such study, which was aimed at determining the key factors influencing elderly users' intention to adopt the m-health services, stated that SI emerged as one of BI's three direct determinants to use technology (Hoque \& Sorwar, 2017).

Seventh, FC has a significant relationship with BI. Users of e-government health applications believe that $\mathrm{MOH}$ provides support if they face any problem using the applications. Therefore, they have a high intention to use those applications. A study by Aggelidis and Chatzoglou (2009) examining HIS acceptance by Greek hospital personnel indicated that FC significantly affects BI to use HIS.

\section{Conclusion}

This research examined the e-government health adoption model in SA. With the sudden spread of COVID-19, the $\mathrm{MOH}$ released several mobile health applications (i.e., Tetamman, Mawid, Tabaud, and Tawakkalna) to serve the public in SA. Adopting such technology provides many benefits to health-care providers, such as safer hospital operations and accessibility to patients' data. The study's outcomes offer a theoretical guide to the successful implementation and adoption of m-health applications in SA. The study applied UTAUT, TAM, ISSM, and MSAM to determine the factors that influence adoption of e-government health applications during COVID-19. Seven hypotheses were tested in this research, and all hypotheses were found to have significant influences in adopting e-government health applications. Based on the results and data analysis, SI, FC, PEOU, PU, ATT, IQ, and TR have a significant relationship with BI to affect the public's acceptance of using e-government health applications. The study has confirmed the validity and reliability while testing the relationship between the variables proposed in the research model. In the end, in different contexts, different results can be revealed using the same models.

This study contributes to the literature on organizational technology adoption by examining e-government 
adoption determinants through MOH. The study has validated the UTAUT, TAM, ISSM, and MSAM for demonstrating and foreseeing people's behavior and acceptance of e-government health applications from the theoretical perspective. Therefore, the study contributes to the technology adoption and acceptance literature in the domain of e-health. According to our knowledge, this is the first research paper to have investigated the adoption of e-government health applications launched by MOH in SA during the COVID-19 pandemic.

This work developed a research model for exploring younger and older users' adoption of SA's electronic health services. Despite the contributions the study authors made in this research paper, its limitations would be new opportunities for future work. First, the sample was exclusively citizen and resident users of e-government health application services. The study authors could find differences if the study were conducted in other countries. Second, although this paper's sample includes 785 respondents, it is considered small compared to SA's population. Therefore, caution must be exercised because the findings might not be generalizable to SA's entire population. Third, the demographic information collected in this research paper includes only gender and age, which provide a limited understanding of the sample. The study authors did not test the relative impact of such characteristics on the adoption behavior in this research paper.

Future research could focus on particular groups such as medical staff and IT to further comprehend the adoption behavior. Different measures could also be applied in future studies to investigate in-depth, collect more informative answers, and utilize qualitative methods such as interviews to get more information from seniors. Future work could include other constructs affecting e-government health application adoption, such as demographic variables (e.g., age, gender, level of education, location, and employment). One more construct that should be utilized in future studies is voluntary use because, recently, the use of the Tawakkalna application became mandatory for everyone in SA to be able to enter public places as part of the precautionary measures to limit the spread of COVID-19. This decision was made on November 2, 2020, after the study authors had completed this research (Okaz, 2020b).

\section{References}

Abanumy, A., Al-Badi, A., \& Mayhew, P. (2005). e-Government Website accessibility: in-depth evaluation of Saudi Arabia and Oman. The Electronic Journal of e-government, 3(3), 99-106.

Abramson, M. A., \& Morin, T. L. (Eds.). (2003). E-government 2003. Rowman \& Littlefield.

Absher (2021). About Absher. Retrieved from https://www.absher.sa/wps/portal/individuals/static/footer/about/lut/p/z1/jY5BDoIwEEXP4gFMZ4ZSui1V hwpGxIDYjWFhDImiC-P5VeLGRNHZ_cz7eV94UQvfNbf20Fzbc9ccH3nr1U5RZjHRIEKIJrCaUq7DGR Kkgdj0ADgpE5SUMigCUxVaT12IrKTwz_eXM_DqM6JJiCFjLghW1mAQmRg1hn3_p38A-Msf2tw6vQiQ 8

Adellia, N., \& Prasetio, A. (2016, April). Customer perception mapping analysis of Indonesian e-commerce marketplace sites based on attributes usability, site design, information quality, trust, and empathy (Case study of Tokopedia, Bukalapak, Elevenia, Qool0, and Rakuten) [Paper presentation]. 2016 Fourth International Conference on Cyber and IT Service Management, Bandung, Indonesia. https://doi.org/10.1109/CITSM.2016.7577580

Agarwal, R., \& Prasad, J. (1998). A conceptual and operational definition of personal innovativeness in the domain of information technology. Information Systems Research, 9, 204-215.

Aggelidis, V. P., \& Chatzoglou, P. D. (2009). Using a modified technology acceptance model in hospitals. International Journal of Medical Informatics, 78(2), 115-126. https://doi.org/10.1016/j.ijmedinf.2008.06.006

Ahn, T., Ryu, S., \& Han, I. (2007). The impact of Web quality and playfulness on user acceptance of online retailing. Information \& management, 44(3), 263-275.

Ajzen, I. (1991). The theory of planned behavior. Organizational Behavior and Human Decision Processes, 50(2), 179-211.

Al-Aboudi, I., Hassali, M., Shafie, A., Alrubeaan, K., \& Hassan, A. (2016). Knowledge, attitudes, and quality of life of type 2 diabetes patients in Riyadh, Saudi Arabia. Journal of Pharmacy and Bioallied Sciences, 8(3), 195. https://doi:10.4103/0975-7406.171683

Al-Ajam, A. S., \& Nor, K. M. (2013). Internet banking adoption: Integrating technology acceptance model and trust. European Journal of Business and Management, 5(3). 
Alateyah, S., Crowder, R. M., \& Wills, G. B. (2013). Factors affecting the citizen's intention to adopt e-government in Saudi Arabia. International Journal of Social, Human Science and Engineering, 7(9).

AlBar, A. M., \& Hoque, M. R. (2019). Patient acceptance of e-health services in Saudi Arabia: An integrative perspective. Telemedicine and e-Health, 25(9).

Aldosari, B. (2012). User acceptance of a picture archiving and communication system (PACS) in a Saudi Arabian hospital radiology department. BMC medical informatics and decision making, 12(1), 1-10.

Aleqtisadiah. (2020, May 4). "SDAIA" Launches the "Tawakkulna" Application to Manage Electronic Permits during the Curfew. Retrieved from https://www.aleqt.com/2020/05/04/article_1819406.html

Alfarraj, O., Alhussain, T., \& Abugabah, A. (2013). Identifying the factors influencing the development of egovernment in saudi arabia: The employment of grounded theory techniques. International Journal of Information and Education Technology, 3(3), 319.

Alhashmi, S. F., Salloum, S. A., \& Abdallah, S. (2019, October). Critical success factors for implementing artificial intelligence (AI) projects in Dubai government United Arab Emirates (UAE) health sector: Applying the extended technology acceptance model (TAM) [Paper presentation]. International Conference on Advanced Intelligence Systems and Informatics.

Ali, F., Rasoolimanesh, S. M., Sarstedt, M., Ringle, C. M., \& Ryu, K. (2018). An assessment of the use of partial least squares structural equation modeling (PLS-SEM) in hospitality research. International Journal of Contemporary Hospitality Management.

Aljohani, N., \& Chandran, D. (2019). Adoption of m-health applications: The Saudi Arabian healthcare perspectives [PDF]. https://acis2019.io/pdfs/ACIS2019_PaperFIN_045.pdf

Almajali, D. A., Maqableh, M., \& Masa'deh, R. (2015). Assessing the digital divide status of the Jordanian telecentre. International Journal of Communications, Network and System Sciences, 8(11), 428-439. https://doi.org/10.4236/ijens.2015.811039

Almuraqab, N. A. S. (2016). M-government adoption factors in the United Arab Emirates: A partial least-squares approach. International Journal of Business and Information, 11(4), 404-431.

Alsajjan, B., \& Dennis, C. (2010). Internet banking acceptance model: Cross-market examination. Journal of Business Research, 63(9-10), 957-963.

Alsharo, M., Alnsour, Y., \& Al-Aiad, A. (2021). Exploring the change of attitude among healthcare professionals toward adopting a national health information system: the case of Jordan. International Journal of Business Information Systems, 36(1), 50-70.

Alshehri, M., \& Drew, S. (2012). A comprehensive analysis of e-government services adoption in Saudi Arabia: Obstacles and challenges. International Journal of Advanced Computer Science and Applications, 3(2), 01-06. https://doi:10.14569/ijacsa.2012.030201

Al-Sudairi, T. M. (1994). A strategic approach to developing information systems in the Kindom of Saudi Arabia (Doctoral dissertation, London School of Economics and Political Science (University of London)).

Alsulame, K., Khalifa, M., \& Househ, M. (2016). E-health status in Saudi Arabia: A review of current literature. Health Policy and Technology, 5(2), 204-210. https://doi:10.1016/j.hlpt.2016.02.005

Altun, Ö. (2018). Factors contributing to the intention of users to adopt beacon technology supported mobile fitness instructor application in fitness centers. [Thesis, Middle East Technical University]. Retrieved from http://etd.lib.metu.edu.tr/upload/12622149/index.pdf

Al-Turki, S. M., \& Tang, N. K. (1998). Information technology environment in Saudi Arabia: a review. Leicester University Management Centre.

Amaro, S., \& Duarte, P. (2015). An integrative model of consumers' intentions to purchase travel online. Tourism management, 46, 64-79.

Amin, J., Siddiqui, A. A., Al-Oraibi, S., Alshammary, F., Amin, S., Abbas, T., \& Alam, M. K. (2020). The potential and practice of telemedicine to empower patient-centered healthcare in Saudi Arabia. International Medical Journal, 27(2), 151-154.

Ammenwerth, E., Iller, C., \& Mahler, C. (2006). IT adoption and the interaction of task, technology and individuals: A fit framework and a case study. BMC Medical Informatics and Decision Making, 6(1), 3. 
Ashraf, A. R., Thongpapanl, N., \& Auh, S. (2014). The application of the technology acceptance model under different cultural contexts: The case of online shopping adoption. Journal of International Marketing, 22(3), 68-93.

Baatia, A. A. (2017, October 21). The Concept of e-health and its history in Saudi Arabia. Retrieved from http://m-quality.net/?p=22839

Bamufleh, D. (2021). Modelling the Acceptance and Use of Electronic Medical Records from Patients' Point of View: Evidence from Saudi Arabia. International Journal of Business and Management, 16(7), 12-31. https://doi.org/10.5539/ijbm.v16n7p12

Bamufleh, D., Almalki, M. A., Almohammadi, R., \& Alharbi, E. (2021). User Acceptance of Enterprise Resource Planning (ERP) Systems in Higher Education Institutions: A Conceptual Model. International Journal of Enterprise Information Systems (IJEIS), 17(1), 144-163.

Bamufleh, D., Hussain, R., Sheikh, E., \& Khodary, K. (2020). Students' Acceptance of Simulation Games in Management Courses: Evidence from Saudi Arabia. Journal of Education and Learning, 9(4), 55.

Basole, R. C. (2004, September). The value and impact of mobile information and communication technologies. In Proceedings of the IFAC Symposium on Analysis, Modeling \& Evaluation of Human-Machine Systems (Vol. 9, pp. 1-7).

Bennani, A. E., \& Oumlil, R. (2014). IT acceptance by nurses in Morocco: Application of a modified unified theory of acceptance and use of technology. IBIMA Business Review, 2014, 1.

Böhm, M., Fuchs, S., Pfliegl, R., \& Kölbl, R. (2009). Driver behavior and user acceptance of cooperative systems based on infrastructure-to-vehicle communication. Journal of the Transportation Research Board, $2129,136-144$.

Carmines, E. G., \& Zeller, R. A. (1979). Reliability and validity assessment. Sage Publications.

Chen, R. F., \& Hsiao, J. L. (2012). An empirical study of physicians' acceptance of hospital information systems in Taiwan. Telemedicine and e-Health, 18(2), 120-125.

Cohen, J., Bancilhon, J. M., \& Jones, M. (2013). South African physicians' acceptance of e-prescribing technology: an empirical test of a modified UTAUT model. South African Computer Journal, 50.

Crosson, J. C., Etz, R. S., Wu, S., Straus, S. G., Eisenman, D., \& Bell, D. S. (2011). Meaningful use of electronic prescribing in 5 exemplar primary care practices. Annals of Family Medicine, 9(5), 392-397.

Davis, F. D. (1989). Perceived usefulness, perceived ease of use, and user acceptance of information technology. MIS Quarterly, 13(3), 319-340.

Davis, F. D., Bagozzi, R. P., \& Warshaw, P. R. (1989). User acceptance of computer technology: A comparison of two theoretical models. Management Science, 35(8), 982-1002.

DeLone, W. H., \& McLean, E. R. (1992). Information systems success: The quest for the dependent variable. Information Systems Research, 3(1), 60-95.

Diamantopoulos, A., \& Siguaw, J. A. (2006). Formative versus reflective indicators in measure development: A comparison and empirical illustration. British Journal of Management, 17(4), 263-282.

Domenichiello, M. (2015). State of the art in adoption of e-health services in Italy in the context of European Union e-government strategies. Procedia Economics and Finance, 23, 1110-1118. https://doi:10.1016/s2212-5671(15)00364-0

Dutta, B., Peng, M. H., \& Sun, S. L. (2018). Modeling the adoption of personal health record (PHR) among individual: the effect of health-care technology self-efficacy and gender concern. Libyan Journal of Medicine, 13(1).

Eid, R., Selim, H., \& El-Kassrawy, Y. (2020). Understanding citizen intention to use m-government services: An empirical study in the UAE. Transforming Government: People, Process and Policy, https://doi.org/10.1108/TG-10-2019-0100

Fishbein, M., \& Ajzen, I. (1975). Belief, attitude, intention, and behavior: An introduction to theory and research. Addison-Wesley.

Fornell, C., \& Larcker, D. F. (1981). Evaluating structural equation models with unobservable variables and measurement error. Journal of Marketing Research, 18(1), 39-50. 
Gadabu, A. (2020). To Use or Not to Use. Investigating M-health Acceptance by Citizens in Malawi Using UTAUT and Trust. North American Academic Research, 3(4), 453-489. https://doi:10.5281/zenodo.3756213

Gajanayake, R., Iannella, R., \& Sahama, T. (2016). An insight into the adoption of accountable-eHealth systems: An empirical research model based on the Australian context. IRBM, 37(4), 219-231. https://doi.org/10.1016/j.irbm.2016.01.002

Gao, S., Krogstie, J., \& Gransæther, P. A. (2008, August). Mobile services acceptance model [Paper presentation]. 2008 International Conference on Convergence and Hybrid Information Technology, Location.

Gao, S., Krogstie, J., \& Siau, K. (2014). Adoption of mobile information services: An empirical study. Mobile Information Systems, 10(2), 147-171. https://doi:10.3233/MIS-130176

Global Health Exhibition. (2020, May 5). Saudi Arabia's digital healthcare landscape post-COVID-19. Retrieved from https://www.globalhealthsaudi.com/en/overview/saudi-news/Saudi-Arabias-digital-healthcare-landscape-po st-COVID-19.html

Global Health Security Index. (2019, October). Report and model: Executive summary. Retrieved from https://www.ghsindex.org/report-model/

Hair, J. F. Jr., Hult, G. T. M., Ringle, C., \& Sarstedt, M. (2016). A primer on partial least squares structural equation modeling (PLS-SEM). Sage Publications.

Hair, J. F. Jr., Matthews, L. M., Matthews, R. L., \& Sarstedt, M. (2017). PLS-SEM or CB-SEM: Updated guidelines on which method to use. International Journal of Multivariate Data Analysis, 1(2), 107-123.

Hair, J. F., Ringle, C. M., \& Sarstedt, M. (2011). PLS-SEM: Indeed a silver bullet. Journal of Marketing theory and Practice, 19(2), 139-152.

Heijden, H. V. D. (2004). User acceptance of hedonic information systems. MIS Quarterly, 28, 695-704.

Hofstede, G. (1997). Cultures and organizations: Software of the mind. McGraw-Hill.

Hoque, M., Bao, Y., \& Sorwar, G. (2017). Investigating factors influencing the adoption of e-Health in developing countries: A patient's perspective. Informatics for Health and Social Care, 42(1), 1-17. https://doi.org/10.3109/17538157.2015.1075541

Hoque, R., \& Sorwar, G. (2017). Understanding factors influencing the adoption of mHealth by the elderly: An extension of the UTAUT model. International Journal of Medical Informatics, 101, 75-84.

Hsu, C. L., \& Lu, H. P. (2004). Why do people play on-line games? An extended TAM with social influences and flow experience. Information \& management, 4l(7), 853-868.

Ismail, A., Jamil, A. T., Rahman, A. F. A., Bakar, J. M. A., Saad, N. M., \& Saadi, H. (2010). The implementation of Hospital Information System (HIS) in tertiary hospitals in Malaysia: a qualitative study. Malaysian Journal of Public Health Medicine, 10(2), 16-24.

Kaushal, R., Kern, L. M., Barrón, Y., Quaresimo, J., \& Abramson, E. L. (2010). Electronic prescribing improves medication safety in community-based office practices. Journal of General Internal Medicine, 25(6), 530-536.

Khalil, M., \& Jones, R. (2007). Electronic health services: An introduction to theory and application. Libyan Journal of Medicine, 2(4), 202-210. https://doi:10.4176/071117

Kharel, P., \& Shakya, S. (2012). E-government implementation in Nepal: A challenge. International Journal of Advanced Research in Computer Science and Software Engineering, 2(1).

Kuo, Y. F., \& Yen, S. N. (2009). Towards an understanding of the behavioral intention to use 3G mobile value-added services. Computers in Human Behavior, 25(1), 103-110.

Lin, H. F. (2007). The role of online and offline features in sustaining virtual communities: An empirical study. Internet Research, 17(2), 119-138.

Machdar, N. M. (2019). The effect of information quality on perceived usefulness and perceived ease of use. Business and Entrepreneurial Review, 15(2), 131-146.

Mardiana, S., Tjakraatmadja, J., \& Aprianingsih, A. (2015). Validating the conceptual model for predicting intention to use as part of the information system success model: The case of an Indonesian government 
agency. Procedia Computer Science, 72, 353-360. https://doi:10.1016/j.procs.2015.12.150

Masrom, M. (2007). Technology acceptance model and e-learning. Technology, 21(24), 81.

Matthew, P. H., \& Kan, L. R. (2017, June 7). Theory of planned behavior. Retrieved from https://link.springer.com/referenceworkentry/10.1007\%2F978-3-319-28099-8_1191-1

Melas, C. D., Zampetakis, L. A., Dimopoulou, A., \& Moustakis, V. (2011). Modeling the acceptance of clinical information systems among hospital medical staff: An extended TAM model. Journal of Biomedical Informatics, 44(4), 553-564. https://doi:10.1016/j.jbi.2011.01.009

Ministry of Communication and Information Technology (MICT). (2020). Brief history. Retrieved from https://www.mcit.gov.sa/en/brief-history

Ministry of Health (MOH). (2018, July 2). Mawid service. Retrieved from https://www.moh.gov.sa/en/eServices/CASINFO/Pages/default.aspx

Ministry of Health (MOH). (2019, September 8). About MOH Portal. Retrieved from https://www.moh.gov.sa/en/Portal/Pages/default.aspx\#: :text=Vision\%3A\%20To\%20be\%20the\%20most,o f\%20participation\%20and\%20constructive\%20dialogue

Ministry of Health (MOH). (2020a). Important self-assessment service launched. Retrieved from https://covid19awareness.sa/archives/4333

Ministry of Health (MOH). (2020b). E-services (Mawid) service. Retrieved from https://www.moh.gov.sa/en/eServices/Pages/cassystem.aspx

Ministry of Health (MOH). (2020c). MOH apps for smartphones. Retrieved from https://www.moh.gov.sa/en/Support/Pages/MobileApp.aspx

Ministry of Health (MOH). (2020d). Tetamman app. Retrieved from https://www.moh.gov.sa/en/eServices/Pages/Rest-assured.aspx

Ministry of Health (MOH). (2021) The MOH initiatives related to the NTP 2020 and Saudi Vision 2030. Retrieved from https://www.moh.gov.sa/en/Ministry/nehs/Pages/vision2030.aspx

Mosnaim, G. S., Stempel, D. A., Gonzalez, C., Adams, B., BenIsrael-Olive, N., Gondalia, R., \& Szefler, S. (2021). The impact of patient self-monitoring via electronic medication monitor and mobile app plus remote clinician feedback on adherence to inhaled corticosteroids: a randomized controlled trial. The Journal of Allergy and Clinical Immunology: In Practice, 9(4), 1586-1594.

Moustapha, A. R. (2019, August 19). What is technology adoption and what are its 5 stages? Retrieved from https://www.exceeders.com/blog/what-is-technology-adoption-and-what-are-its-5-stages

Naar, I. (2020, March 21). Coronavirus: Saudi Arabia's Mawid app guides on self-isolation or hospital visit. Retrieved from https://english.alarabiya.net/en/media/digital/2020/03/21/Coronavirus-Saudi-Arabia-s-Mawid-app-guides-o n-self-isolation-or-hospital-visit

Ndou, V. D. (2004). E-government for developing countries: Opportunities and challenges. Electronic Journal of Information Systems in Developing Countries, 18(1), 1-24. https://doi:10.1002/j.1681-4835.2004.tb00117.x

Nunnally, J. C. (1978). An overview of psychological measurement. Clinical Diagnosis of Mental Disorders, $97-146$.

Okaz. (2020a). "SDAIA" Launches the Application of "Tabaud" To Notify Users Who Are In Contact. Retrieved from https://www.okaz.com.sa/news/local/2028404

Okaz. (2020b). "Madinah Principality": "Tawakkulna" is Mandatory for Entry into Government and private agencies. Retrieved from https://www.okaz.com.sa/news/local/2046777

Okour, K., Alharbi, M., \& Alazzam, M. (2019). Identify Factors That Influence Healthcare Quality By Adoption Mobile Health Application In KSA E-Health. Indian Journal of Public Health Research and Development, 10(11), 2409. https://doi:10.5958/0976-5506.2019.03967.6

Or, C. K., Karsh, B. T., Severtson, D. J., Burke, L. J., Brown, R. L., \& Brennan, P. F. (2011). Factors affecting home care patients' acceptance of a web-based interactive self-management technology. Journal of the American Medical Informatics Association, 18(1), 51-59.

Orruño E., Gagnon, M. P., Asua, J., \& Ben Abdeljelil, A. (2011). Evaluation of teledermatology adoption by 
health-care professionals using a modified technology acceptance model. Journal of Telemed and Telecare, 17(6), 303-307. https://doi:10.1258/jtt.2011.101101

Ramdani, B., Duan, B., \& Berrou, I. (2020). Exploring the determinants of mobile health adoption by hospitals in China: Empirical study. JMIR Medical Informatics, 8(7), e14795. https://doi:10.2196/14795

Rogers, E. M., \& Shoemaker, F. F. (1971). Communication of innovations: A cross-cultural approach. Free Press.

Sabq. (2020, March 24). Al-Rabiah tweets titled "Important and Urgent": If you doubt the symptoms of "Corona", check with "Self-Assessment". Retrieved from https://mobile.sabq.org/hV7TSf

Sait, S. M., Al-Tawil, K., Ali, S., \& Ali, H. (2003). Use and effect of internet in Saudi Arabia [PDF]. Retrieved from https://core.ac.uk/download/pdf/146509963.pdf

Saprikis, V., Markos, A., Zarmpou, T., \& Vlachopoulou, M. (2018). Mobile shopping consumers' behavior: An exploratory study and review. Journal of Theoretical and Applied Electronic Commerce Research, 13(1), 71-90. https://doi:10.4067/s0718-18762018000100105

Saudi Data \& Artificial Intelligence Authority (SDAIA). (2020a). About Tawakkalna. Retrieved from https://ta.sdaia.gov.sa/en/index

Saudi Data \& Artificial Intelligence Authority (SDAIA). (2020b). About Tabaud Application. Retrieved from https://tabaud.sdaia.gov.sa/IndexEn

Saurabh, C. (2017). Digital India: The move towards E-Government transformation. Multi Disciplinary Edu Global Quest, 6(2), 181-196.

Sezgin, E., Alaşehir, O., \& Yıldırım, S. (2014). Work in progress toward adoption of an e-health application by healthcare personnel: A model validation. Procedia Technology, 16, 1327-1333. https://doi:10.1016/j.protcy.2014.10.149

Shkarlet, S., Oliychenko, I., Dubyna, M., Ditkovska, M., \& Zhovtok, V. (2020). Comparative analysis of best practices in e-Government implementation and use of this experience by developing countries. Administratie si Management Public, 34, 118-136.

Tapscott, D. (1996). The digital economy: Promise and peril in the age of networked intelligence (Vol. 1). New York: McGraw-Hill.

Taylor, S., \& Todd, P. (1995a) Assessing IT usage: The role of prior experience. MIS Quarterly, 19(4), 561-570.

Taylor, S., \& Todd, P. A. (1995b). Understanding information technology usage: A test of competing models. Information Systems Research, 6(4), 149.

Thompson, R. L., Higgins, C. A., \& Howell, J. M. (1991). Personal computing: Toward a conceptual model of utilization. MIS quarterly, 125-143.

Tornatzky, L. G., Fleischer, M., \& Chakrabarti, A. K. (1990). Processes of technological innovation. Lexington books.

Tran, V., Zhao, S., Diop, E. B., \& Song, W. (2019). Travelers' acceptance of electric carsharing systems in developing countries: The case of China. Sustainability, 11(19), 5348. https://doi:10.3390/su11195348

Triandis, H. C. (1980). Values, attitudes, and interpersonal behavior [Paper presentation]. Nebraska Symposium on Motivation, Lincoln, NB.

Turban, E., Outland, J., King, D., Lee, J. K., Liang, T. P., \& Turban, D. C. (2017). Electronic commerce 2018: a managerial and social networks perspective. Springer.

Venkatesh, V., Morris, M. G., Davis, G. B., \& Davis, F. D. (2003). User acceptance of information technology: Toward a unified view. MIS Quarterly, 27(3), 425-478. https://doi.org/10.2307/30036540

Verkijika, S. F., \& De Wet, L. (2018). E-government adoption in sub-Saharan Africa. Electronic Commerce Research and Applications, 30, 83-93. https://doi.org/10.1016/j.elerap.2018.05.012

Wahdain, E., \& Ahmad, M. N. (2014). User acceptance of information technology: Factors, theories and applications. Journal of Information Systems Research and Innovation, 19, 17-25. Retrieved from https://seminar.utmspace.edu.my/jisri/download/F_Vol6Feb2014_FullPaper/Pub3_UserAcceptanceofIT.pdf

Weng, F., Yang, R., Ho, H., \& Su, H. (2018). A TAM-based study of the attitude towards use intention of multimedia among school teachers. Applied System Innovation, 1(3), 36. https://doi:10.3390/asi1030036 
Williamson, W., \& Parolin, B. (2013). Investigating e-planning in practice: Applying the unified theory of acceptance and use of technology model. International Journal of E-Planning Research, 2(3), 17-29.

Witarsyah, D. (2018). An optimized electronic government Services adoption model using Structural equation and maximum Attribute relative models (Doctoral dissertation, Universiti Tun Hussein Onn Malaysia).

World Health Organization. (2020). Eastern Mediterranean region. Retrieved from http://www.emro.who.int/media/news/who-saudi-arabia-join-forces-to-fight-covid-19-nationally-regionally -and-globally.html

Yakubu, M. N., \& Dasuki, S. (2018). Assessing eLearning systems success in Nigeria: An application of the DeLone and McLean Information Systems Success model. Journal of Information Technology Education: Research, 17, 182-202. https://doi.org/10.28945/4077

Yusif, S., Hafeez-Baig, A., \& Soar, J. (2020). A model for evaluating eHealth preparedness: A case study approach. Transforming Government: People, Process and Policy, 14(3), 561-587. https://doi.org/10.1108/TG-07-2019-0069

Zulfan, Z. (2018). An information system success model for cloud computing in information technology project. Cyberspace: Jurnal Pendidikan Teknologi Informasi, 2(1), 18. https://doi:10.22373/cs.v2i1.2661

\section{Copyrights}

Copyright for this article is retained by the author(s), with first publication rights granted to the journal.

This is an open-access article distributed under the terms and conditions of the Creative Commons Attribution license (http://creativecommons.org/licenses/by/4.0/). 